\title{
OPTIMIZING SIGNAL PHASE PLAN, GREEN SPLITS AND LANE LENGTH FOR ISOLATED SIGNALIZED INTERSECTIONS
}

\author{
Ronghan Yao ${ }^{1}$, Hongmei Zhou ${ }^{2}$, Ying-En Ge ${ }^{3}$ \\ ${ }^{1,2}$ School of Transportation and Logistics, Faculty of Infrastructure Engineering, \\ Dalian University of Technology, China \\ ${ }^{3}$ Dept of Management, College of Transport and Communications, Shanghai Maritime University, China
}

Submitted 11 June 2015; resubmitted 28 September 2015, 15 November 2015, 21 December 2015; accepted 14 January 2016; published online 27 April 2017

\begin{abstract}
At an isolated signalized intersection, short left-turn lanes may be provided to enhance intersection capacity and level of service. The capacity of an entire intersection depends not only on the effective green time per phase and the length of each short left-turn lane but also on the selected signal phase plan. This paper enumerates 16 typical signal phase plans for a four-leg intersection with protected left-turn phases. Given the existence of short left-turn lanes and the freedom to select signal phase plans, two optimization models are formulated. Numerical examples are carried out to illustrate the application of these models and show the sensitivity of the outcomes to impact factors. The orthogonal experiments show that the primary factor is whether a short left-turn lane is added on an approach and the demand distribution is the secondary factor in determining an optimal allocation of the time-space resources of an intersection. To analyse traffic flow operations under different signal phase sequences, the simulation tests are fulfilled using VISSIM under the assumption that the components of a signal phase plan and green splits are all identical. The simulated results indicate that the signal phase sequence for a specified approach may greatly affect traffic movements at an approach, and the leading green phasing is better than the lagging one for a specified approach when the left-turn bay length is short at the approach. Finally, two variations of the developed models are recommended for use and the procedure for the model application is provided in practice.
\end{abstract}

Keywords: isolated intersections; signal phase plan; lane length; signal timing; short left-turn lanes; capacity-to-delay ratio.

\section{Introduction}

To improve the safety and efficiency of traffic flow operations, traffic signals are installed at many intersections. Since traffic signal settings at an intersection plays an important role in determining the capacity and level of service of the intersection, a large number of efforts have been made to optimize signal phase plans and signal timings. To accommodate heavy left-turn traffic, protected left-turn phases are usually provided along with the corresponding exclusive left-turn lanes. Due to the limited road space at an intersection approach, left-turn lanes often exist in the form of short-lanes or turn bays. Short-lanes, often called turn bays, refer to those lanes, that are added on the approaches in order to improve the capacity of an intersection. However, only a limited number of studies discuss the effects of short-lanes on traffic flow operations at signalized intersection.
Signal timings are usually determined based on a pre-determined phase plan, which is usually done by means of the dual-ring design technique (Akçelik 1998; Highway Capacity Manual 2000; RTRA 2003; Koonce et al. 2008; Roess et al. 2010). Webster (1958) first proposed an optimal cycle length formula obtained by minimizing the total delay for all vehicles at an isolated intersection. However, the cycle length given by this formula heavily depends on the critical flow ratio for the entire intersection. If the critical flow ratio approaches one, the estimated cycle length will be unreasonably large, that is, the estimated value will be larger than the recommended maximum value (Highway Capacity Manual 2000), if it is equal to or greater than one, the formula will be inapplicable. The optimal cycle length formula given in Akçelik (1998) was derived by minimizing the performance measure defined by the total delay and the

Corresponding author: Ying-En Ge

E-mail: yege@shmtu.edu.cn 
number of stops for all critical movements at an isolated intersection. The stop penalty parameter was also introduced in this reference. However, it is difficult to choose an appropriate parameter value because many factors (e.g. fuel consumption, operating expenses, and vehicle delay) need to be taken into consideration. When the parameter equals zero, the cycle length estimated by Akçelik's formula is very close to that by Webster's formula. Once the optimum cycle length is determined by the sum of critical flow ratios and the total lost time per cycle, the total effective green time is assigned to the signal phases in proportion to the critical flow ratio or the arrival flow rate corresponding to each phase. When there is no overlapping movement in a phase plan, if the lost times are the same for all the movements in a phase, the critical movement in the phase is identified as the one with the largest flow ratio (Webster, Cobbe 1966; Highway Capacity Manual 2000); if the saturation flow rates as well as the lost times are the same for all the movements in the phase, the critical movement is identified as the one with the highest arrival flow rate (Roess et al. 2010). When overlapping movements appear, the identification of critical movements may be more complex. In either case, such identification can be carried out by using search diagram (Akçelik 1998) or ring diagram (Highway Capacity Manual 2000; Roess et al. 2010). Additionally, some researchers proposed the lane-based optimization of signal timings for the integrative design of lane markings and signal settings for an isolated junction (Lam et al. 1997; Wong, C., Wong, S. 2003). To determine the optimal allocation of time-space resources at a signalized intersection, Wong and Heydecker (2011) extended the previous work by relaxing the number of lanes on each approach as a new integer variable. The resulting formulation can determine the optimal lane arrangement for each approach to manage the certain traffic demands more efficiently.

In the past decades, some researchers also studied the effects of short-lanes on the operations of signalized intersections, e.g. the effects on saturation flow rate, capacity, delay and waiting time, etc. Akçelik (1998) first pointed out that the saturation flow rate for the lane group with a short-lane was not constant and presented the formula of the equivalent saturation flow rate for the lane group. Considering the stochastic nature of traffic flow, Wu (2007, 2011), and Tian and Wu (2006) proposed the capacity estimation models for signalized intersections with short turn lanes in different cases. Zhang and Tong (2008) presented a probabilistic model of the capacity calculation for the left-turn and through movements, which is a function of the left-turn bay length. Yin et al. $(2010,2011)$ developed the analytical models of the capacity estimation for protected and permitted left-turn traffic with short left-turn bays and the probabilistic models of the delay estimation for the left-turn and through vehicles under protected left-turn operations at signalized intersections.

In addition, some scholars focus on the determination of the appropriate length of a short left-turn lane. Kikuchi et al. $(2004,2007)$ developed the procedures to determine the required length of a short left-turn lane in different conditions. To prevent lane overflow and the blockage of lane entrance, Qi et al. $(2007,2012)$ put forward the procedures to determine the queue storage length and deceleration length of the left-turn lane by evaluating the analytical-based and simulation-based methods. Yang and Zhou (2011) presented a new methodology to coordinate the geometric design of left-turn lanes with signal timing for signalized intersections.

The research on signal timing optimization generally neglects the effects of short-lanes on the operations of signalized intersections because short-lanes are basically regarded as full lanes (Highway Capacity Manual 2000; Roess et al. 2010). Since such a treatment ignores the blockage effects of short-lanes on the intersection capacity, the capacity and delay could not be accurately estimated for the entire intersection. On the other hand, the research on short-lanes rarely take into account the design of signal phase plans, particularly the complicated overlapping phasing (Akçelik 1998; Kikuchi et al. 2004, 2007; Tian, Wu 2006; Wu 2007; Yang, Zhou 2011; Qi et al. 2012). They focus on the probabilities of blockage and overflow or the suitable design length of a short left-turn lane based on a certain signal phase plan. The impacts of the change of signal phase plan on the performance or design of short-lanes are not investigated. It is well known that the signal phase plan and the effective green time per phase can reflect the allocation of intersection time resources and the short-lane length can reflect the allocation of intersection space resources. Based on our previous work (Yao 2013; Yao, Zhang 2013), this paper aims at finding the optimal combination of signal phase plan, green splits and required short-lane length so as to achieve the best performance of an intersection.

The previous lane-based signal timing focuses on the integrated optimization of lane markings and signal timings based on variable lane-use and does not consider the channelization of left-turn bays. Under the assumption that the lane grouping is predefined in view of certain traffic demand levels, this paper presents a combined optimization of signal phase plan, green splits and required short-lane length based on variable signal phasing and left-turn bay length. This is an extension of the previous work to further relax the signal phasing as a binary independent variable, which can simultaneously optimize signal timings and left-turn bay lengths. By identifying whether there is a short left-turn lane in each lane group or on each approach, the second intellectual merit of this paper is that a relatively in-depth discussion on the feasibility of the use of capacity-to-delay ratio as the objective of the configuration of a signalized intersection is investigated.

The rest of this paper is organized as follows. Considering the existence of short left-turn lanes and the freedom to select signal phase plans, Section 1 presents two optimization models to achieve the maximum intersection capacity and the minimum intersection delay. In Section 2, numerical examples are carried out to demonstrate the performance and application of the formulated models by orthogonal experiments and analyse the impacts of different signal phase sequences on traffic flow 
operations by simulation tests. Section 3 recommends two variations of the formulated models and introduces a procedure of using the recommended models in practice. Last section closes with some concluding remarks.

\section{Methodology}

\subsection{Assumptions}

For a short-lane, an important design parameter is the short-lane length or left-turn bay length, which can be regarded as the sum of the queue storage length and deceleration length (Qi et al. 2012). When a short leftturn lane exists on an approach, there are two cases, which may occur. On the one hand, left-turn vehicles may overflow from the left-turn lane. On the other hand, the entrance of the left-turn lane may be blocked by the queue of the adjacent through vehicles. follows:

In this paper, the basic assumptions are given as

- the intersection under study, with or without short left-turn lanes, is controlled by pretimed signals during a morning or afternoon peak period of a typical weekday;

- the lost time per transition within a cycle is identical for each signal phase plan;

- the total lost time in a signal cycle and the saturation flow rate for each lane or lane group are known;

- there are only passenger cars in any traffic stream, otherwise, all types of vehicles need to be converted into passenger cars by using the calibrated or ascertained conversion factors;

- the hourly volume and the demand distribution for each lane or lane group are obtained during the peak hour;

- the right-turn traffic is not controlled by specific signal phases but always goes together with the through traffic.

\subsection{Signal Phase Plans}

Considering an intersection with two major streets (Roess et al. 2010), Fig. 1a shows a typical four-leg intersection with a short left-turn lane, an exclusive leftturn lane, a through lane and a shared through-right lane on each approach. This case can be simplified to consider an intersection with a major street and a minor street. It may be also simplified to consider one-way streets or three-leg intersections, and then the signal phase schemes will be simpler. In view of one common practice (Koonce et al. 2008), all traffic movements are coded from M1 to M8, as shown in Fig. 1b.

Assuming that the protected left-turn phase is provided for each approach, there are 12 possible phase diagrams in the east-west direction as shown in Fig. 2, which can be classified into four categories, i.e. exclusive left-turn phasing (PD1 and PD2), left-through phasing (PD3 and PD4), exclusively left-turn plus leading green phasing (or lagging green plus exclusively left-turn phasing) (PD5, PD6, PD7 and PD8), and leading and lagging

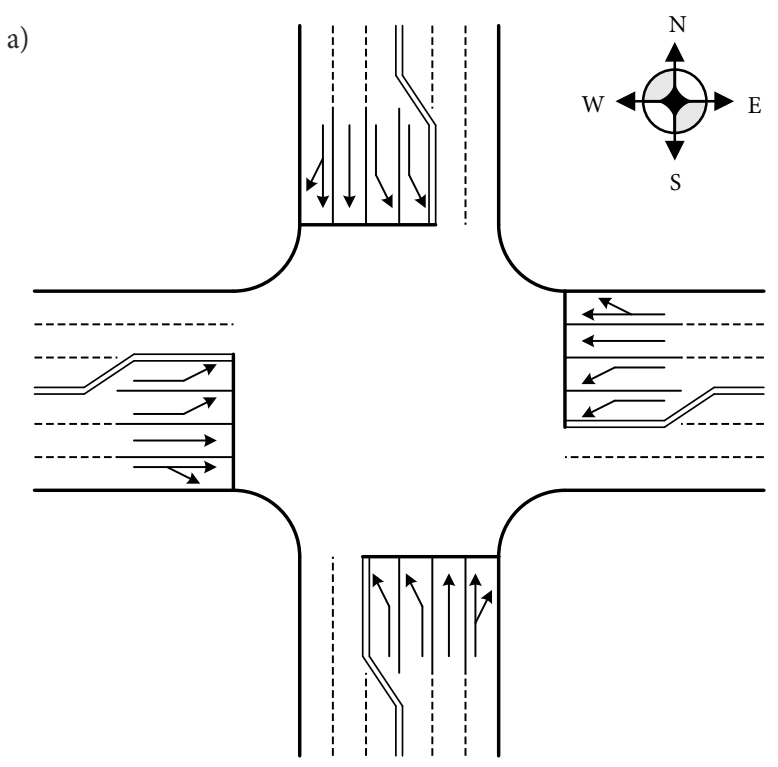

b)

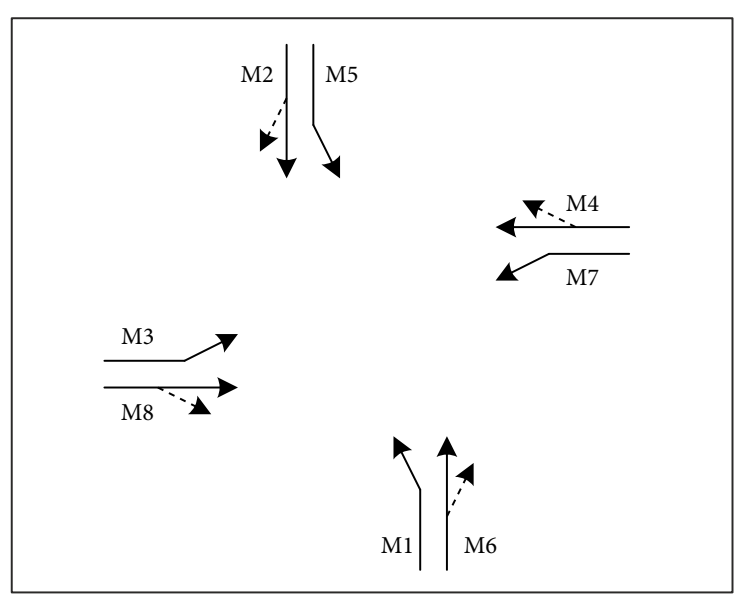

Fig. 1. Intersection layout and movement numbering: $\mathrm{a}$ - intersection layout; $\mathrm{b}$ - movement numbering

green phasing (PD9, PD10, PD11 and PD12). Exclusive left-turn phasing means that the subject and opposing left-turn movements go together, and the subject and opposing through movements go together. Left-through phasing means that the subject left-turn and through movements go together. Leading green means that the subject left-turn movement goes before the opposing through movement, whereas lagging green means that the subject left-turn movement goes behind the opposing through movement. Similarly, there are 12 possible phase diagrams in the south-north direction. Thus, there are a total of 144 combinations of possible phase diagrams for the intersection.

For PD5 and PD7, if the effective green time of the second phase is zero, they are simplified into PD1, in other words, PD1 is a special case of PD5 and PD7. Similarly, PD2 is a special case of PD6 and PD8, PD3 is a special case of PD9 and PD11, and PD4 is a special case of PD10 and PD12. As a whole, exclusively left-turn plus leading green phasing (or lagging green plus exclusively left-turn phasing) and leading and lagging green phasing are more general than exclusive left-turn phasing and 
left-through phasing. Although the phase sequence of PD5 is the reverse of that of PD6, the phase components of PD5 are the same as those of PD6. According to Roess et al. (2010), both of these two-phase diagrams have four discrete phases, and thus the total effective green times are the same as well as the effective green time of each phase component. Therefore, it is with PD7 and PD8, PD9 and PD10, and PD11 and PD12. Then PD5, PD7, PD9 and PD11 are selected as typical phase diagrams and there are 16 combinations of the signal phase plans, which are denoted by SPP1 through SPP16 in Fig. 3 for the entire intersection. a)

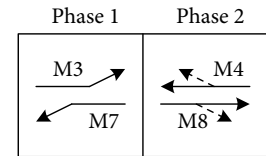

Phase Diagram 1 (PD1)

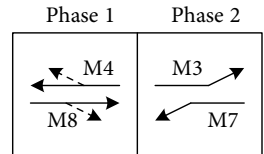

Phase Diagram 2 (PD2) b)

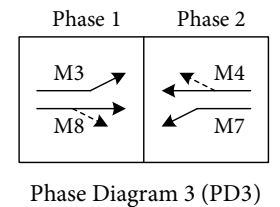

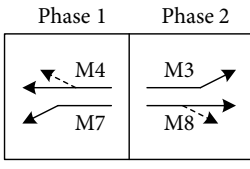

Phase Diagram 4 (PD4)

c)

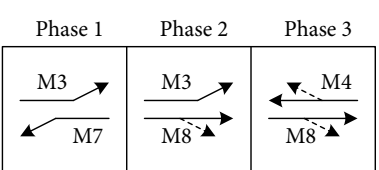

Phase Diagram 5 (PD5)

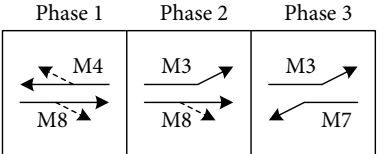

Phase Diagram 6 (PD6)

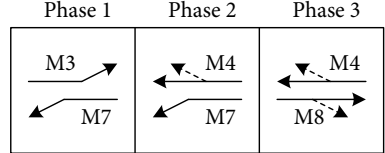

Phase Diagram 7 (PD7)

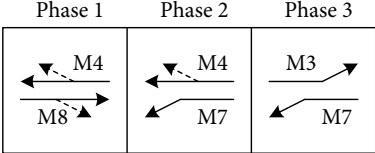

Phase Diagram 8 (PD8)

d)

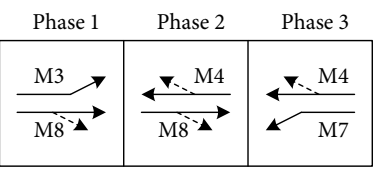

Phase Diagram 9 (PD9)

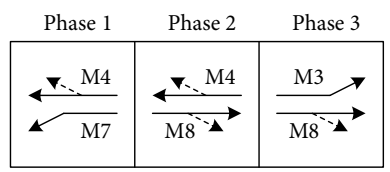

Phase Diagram 10 (PD10)

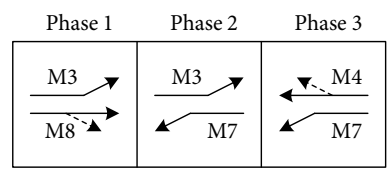

Phase Diagram 11 (PD11)

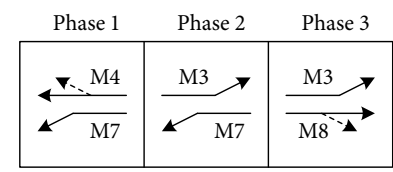

Phase Diagram 12 (PD12)

Fig. 2. Possible phase diagrams in the east-west direction: a - exclusive left-turn phasing; $b$ - left-through phasing; c - exclusively left-turn plus leading green phasing (or lagging green plus exclusively left-turn phasing); $\mathrm{d}$ - leading and lagging green phasing

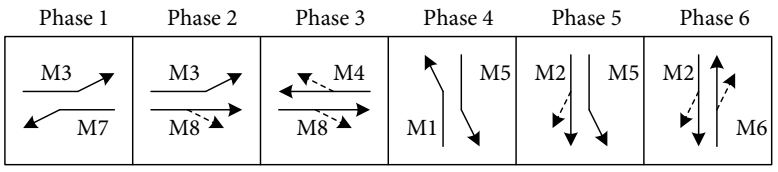

Signal Phase Plan 1 (SPP1)

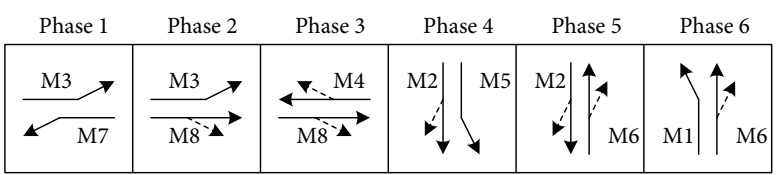

Signal Phase Plan 3 (SPP3)

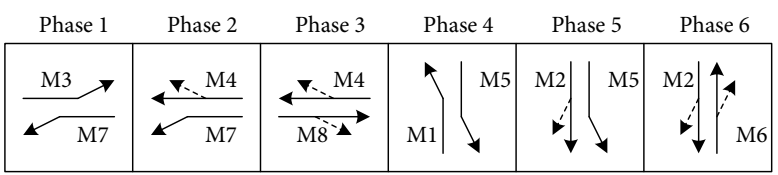

Signal Phase Plan 5 (SPP5)

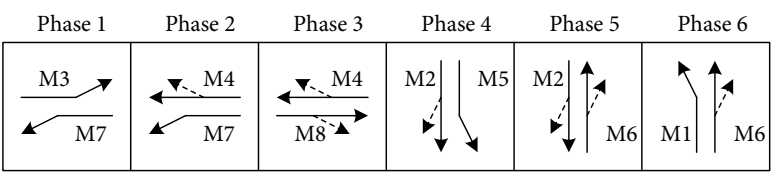

Signal Phase Plan 7 (SPP7)

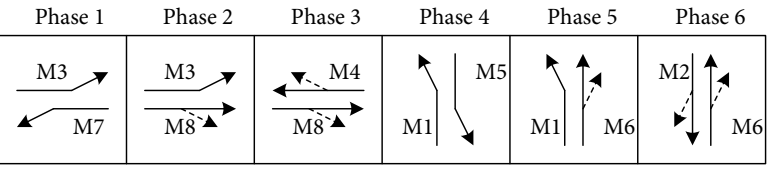

Signal Phase Plan 2 (SPP2)

\begin{tabular}{|c|c|c|c|c|c|c|}
\hline Phase 1 & Phase 2 & Phase 3 & Phase 4 & Phas & & Phase 6 \\
\hline M3 $\longrightarrow$ & M3 & ㄷ. M4 & M2 & & M5 & \\
\hline M7 & $\stackrel{\mathrm{M} \ddot{\mathrm{B}} \mathbf{\mathbf { A }}}{\longrightarrow}$ & $\stackrel{\mathrm{M} \dot{8} \mathbf{\Delta}}{\longrightarrow}$ & $\checkmark$ & & & M1 \\
\hline
\end{tabular}

Signal Phase Plan 4 (SPP4)

\begin{tabular}{|c|c|c|c|c|c|c|}
\hline Phase 1 & Phase 2 & Phase 3 & Phas & & Phase 5 & Phase 6 \\
\hline M3 & …M4 & T. M4 & & M5 & $\uparrow \uparrow$ & M2 $\mid \uparrow_{4}$ \\
\hline & $-\quad N_{1}$ & Mis & M1 & $y$ & M1 & M6 \\
\hline
\end{tabular}

Signal Phase Plan 6 (SPP6)

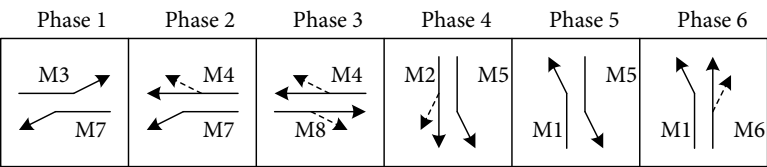

Signal Phase Plan 8 (SPP8) 


\begin{tabular}{|c|c|c|c|c|c|c|c|}
\hline Phase 1 & Phase 2 & Phase 3 & Phas & & Pha & & Phase 6 \\
\hline M3 & ㄷ. M4 & ㄷ.M4 & & M5 & M2 & M5 & M2 \\
\hline $\overrightarrow{\mathrm{M} \stackrel{\longrightarrow}{\longrightarrow}}$ & $\overrightarrow{\mathrm{M} 8 \mathbf{\Delta}}$ & $\mathrm{M} 7$ & M1 & 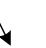 & 1 & & $\checkmark \mathrm{M} 6$ \\
\hline
\end{tabular}

Signal Phase Plan 9 (SPP9)

\begin{tabular}{|c|c|c|c|c|c|c|}
\hline Phase 1 & Phase 2 & Phase 3 & $\mathrm{Pha}$ & & Phase 5 & Phase 6 \\
\hline M3 & T. M4 & M4 & M2 & $\mathrm{M}$ & M2 $\mid \uparrow_{1}$ & $\uparrow 4$ \\
\hline M8. & $\mathrm{M} 8$ & M7 & & & M6 & M1 \\
\hline
\end{tabular}

Signal Phase Plan 11 (SPP11)

\begin{tabular}{|c|c|c|c|c|c|c|c|}
\hline Phase 1 & Phase 2 & Phase 3 & & & $\mathrm{Ph}$ & & Phase 6 \\
\hline M3 & M3 & ㅈ. M4 & & M5 & M2 & M5 & M2 $2 \uparrow_{1}$ \\
\hline $\mathrm{M} 8 \mathbf{A}$ & $\mathrm{M} 7$ & $\mathrm{M} 7$ & M & 4 & $\checkmark$ & 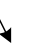 & M6 \\
\hline
\end{tabular}

Signal Phase Plan 13 (SPP13)

\begin{tabular}{|c|c|c|c|c|c|}
\hline Phase 1 & Phase 2 & Phase 3 & Phase 4 & Phase 5 & Phase 6 \\
\hline M3 $\pi$ & M3 & …M4 & M2 & M2 $\mid \uparrow_{4}$ & \\
\hline $\mathrm{MB}$ & $\mathrm{M} 7$ & $\mathrm{M}_{7}$ & $\nabla$ & 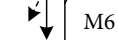 & M1 \\
\hline
\end{tabular}

Signal Phase Plan 15 (SPP15)

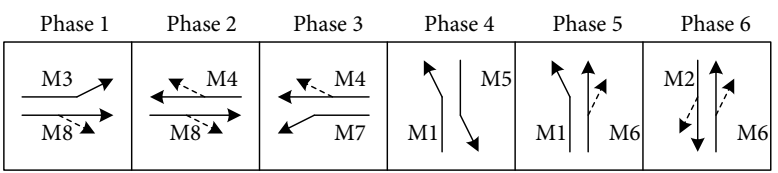

Signal Phase Plan 10 (SPP10)

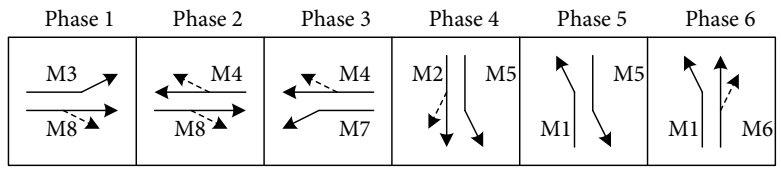

Signal Phase Plan 12 (SPP12)

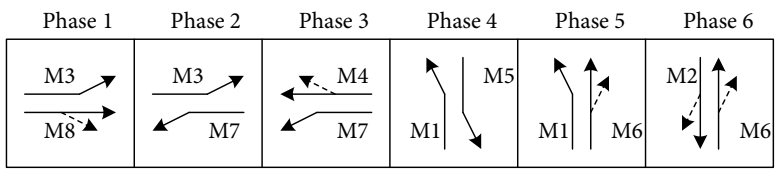

Signal Phase Plan 14 (SPP14)

\begin{tabular}{|c|c|c|c|c|c|c|c|}
\hline Phase 1 & Phase 2 & Phase 3 & Pha & & & se 5 & Phase 6 \\
\hline M3 & M3 $>$ & ‥ M4 & M2 & M5 & & M5 & 4 \\
\hline $\mathrm{M} 8$ & $\mathrm{M} 7$ & M7 & & 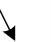 & M1 & 4 & M1 \\
\hline
\end{tabular}

Signal Phase Plan 16 (SPP16)

Fig. 3. Typical signal phase plans

\subsection{Capacity of Lane Group and Intersection}

As illustrated in Fig. 4a, there is a full exclusive left-turn lane denoted by FL and a short left-turn lane denoted by SL in the same lane group on an approach. Based on Akçelik (1998), the number of vehicles which can queue in the short-lane is $D_{k j} / h$, where $D_{k j}$ and $h$ refer to the length of the short-lane and the average queue spacing between consecutive vehicles, respectively, if $k$ means the number of a given signal phase plan and

a)

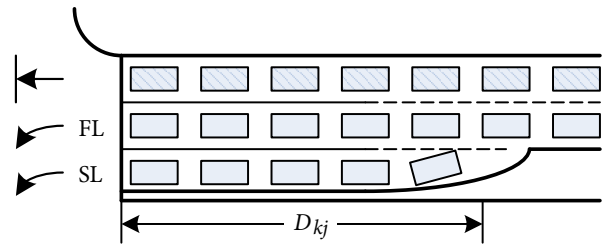

b)

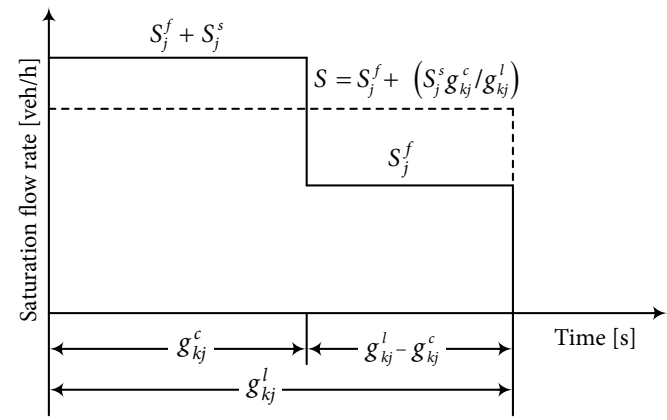

Fig. 4. Saturation flow rate for the lane group with a short left-turn lane: a - lane group with a short left-turn lane; $b$ - time-dependent curve of saturation flow rate $j$ represents the number of a specified lane group. As shown in Fig. 4b, the full saturation flow rate $S_{j}^{f}+S_{j}^{s}$ for the lane group will last for a period $g_{k j}^{c}=\frac{D_{k j}}{h \cdot\left(S_{j}^{f}+S_{j}^{s}\right)}$ and is reduced to $S_{j}^{f}$ (the saturation flow rate for the full left-turn lane) during the period $g_{k j}^{l}-g_{k j}^{c}$ after the signal for this lane group turns green, where $g_{k j}^{l}$ refers to the effective green time for lane group $j$ when phase plan $k$ is adopted. Thus, the capacity per cycle is $S \cdot g_{k j}^{l}=\left(S_{j}^{f}+S_{j}^{s}\right) \cdot g_{k j}^{c}+S_{j}^{s} \cdot\left(g_{k j}^{l}-g_{k j}^{c}\right)$, where $S$ is the average saturation flow rate for the lane group during the green. If there is only a short left-turn lane in the given lane group in Fig. $4 \mathrm{a}, S_{j}^{f}$ is equal to 0 and this case is that a short left-turn lane is adjacent to a through lane. If there is only a full left-turn lane in the given lane group in Fig. $4 \mathrm{a}, S_{j}^{s}$ is equal to 0 and this case is that there is no short left-turn lane. For these two cases, the above capacity calculation of a specified lane group is still right.

Taking the signal phasing into consideration, the capacity of each lane group may be computed as:

$$
\begin{aligned}
& Q_{k j}=\left\{\begin{array}{l}
a_{1} ; \\
a_{2},
\end{array}\right. \\
& a_{1}=\frac{1}{C_{k}}\left(S_{j}^{f} \cdot\left(\sum_{i=1}^{n_{k}} \phi_{k i j} g_{k i}\right)+S_{j}^{s} \cdot g_{k j}^{c}\right), \\
& \sum_{i=1}^{n_{k}} \phi_{k i j} \cdot g_{k i} \geq g_{k j}^{c}, \forall \delta_{k}=1 ; \\
& a_{2}=\frac{1}{C_{k}} \cdot\left(S_{j}^{f}+S_{j}^{s}\right) \cdot\left(\sum_{i=1}^{n_{k}} \phi_{k i j} g_{k i}\right),
\end{aligned}
$$




$$
\sum_{i=1}^{n_{k}} \phi_{k i j} \cdot g_{k i}<g_{k j}^{c}, \forall \delta_{k}=1,
$$

where: $Q_{k j}$ - capacity of lane group $j$ when adopting phase plan $k[\mathrm{veh} / \mathrm{h}] ; C_{k}=\sum_{i=1}^{n_{k}} g_{k i}+L_{k}-$ cycle length for phase plan $k[s] ; n_{k}-$ number of phases in phase plan $k ; g_{k i}$ - effective green time for phase $i$ when adopting phase plan $k[\mathrm{~s}] ; L_{k}$ - total lost time per cycle for phase plan $k[\mathrm{~s}] ; S_{j}^{f}$ - saturation flow rate for the full lanes in lane group $j$ [veh/h]; $S_{j}^{s}$ - saturation flow rate for the short left-turn lane in lane group $j[\mathrm{veh} / \mathrm{h}] ; \phi_{k i j}$ - binary variable indicating whether or not the movements in lane group $j$ have right of way in phase $i$ when adopting phase plan $k ; g_{k j}^{c}=\frac{D_{k j} \cdot t}{h}-$ full discharge time for the queue on the short left-turn lane in lane group $j$ when adopting phase plan $k[s] ; D_{k j}$ - length of the short left-turn lane in lane group $j$ when adopting phase plan $k[\mathrm{~m}] ; t$ - average saturation headway between consecutive vehicles [s]; $h$ - average queue spacing between consecutive vehicles $[\mathrm{m}] ; \delta_{k}$ - binary variable indicating whether phase plan $k$ is adopted or not. There may be no short left-turn lane or no full exclusive left-turn lane in the lane group, and then the saturation flow rate for the short-lane and the short-lane length should be set to 0 or the saturation flow rate for the full lane should be set to 0 , respectively. In any case, there should be at least one full or short-lane for a lane group and the number of full lanes may be more than one.

By aggregating the capacity of all the lane groups, the capacity of the entire intersection (referred to as intersection capacity) can be given by:

$$
Q_{k}=\sum_{j=1}^{m} Q_{k j}, \forall \delta_{k}=1,
$$

where: $Q_{k}$ - intersection capacity when adopting phase plan $k$ [veh/h]; $m$ - number of lane groups.

\subsection{Average Delay for Lane Group and Intersection}

Using the model in Highway Capacity Manual (2000), the average delay per vehicle for each lane group may be estimated as:

$$
\begin{aligned}
& d_{k j}=d_{1 k j} \cdot P F+d_{2 k j}+d_{3 k j}, \\
& \forall \delta_{k}=1 ; \\
& d_{1 k j}=\frac{0.5 \cdot C_{k} \cdot\left(1-\frac{g_{k j}^{l}}{C_{k}}\right)^{2}}{1-\min \left(1, x_{k j}\right) \cdot \frac{g_{k j}^{l}}{C_{k}}} ; \\
& d_{2 k j}=900 \cdot T \cdot\left(\left(x_{k j}-1\right)+\right. \\
& \left.\sqrt{\left(x_{k j}-1\right)^{2}+8 \cdot \kappa \cdot I \cdot \frac{x_{k j}}{T \cdot Q_{k j}}}\right),
\end{aligned}
$$

where: $d_{k j}$ - average delay for lane group $j$ when adopting phase plan $k$ [s/veh]; $d_{1 k j}$ - uniform delay for lane group $j$ when adopting phase plan $k$ [s/veh]; $P F-$ uniform delay progression adjustment factor; $d_{2 k j}$ - incremental delay for lane group $j$ when adopting phase plan $k$ [s/veh]; $d_{3 k j}$ - initial queue delay for lane group $j$ when adopting phase plan $k[\mathrm{~s} / \mathrm{veh}] ; g_{k j}^{l}=\sum_{i=1}^{n_{k}} \phi_{k i j} \cdot g_{k i}-$ effective green time for lane group $j$ when adopting phase plan $k ; x_{k j}=\frac{q_{j}}{Q_{k j}}$ - degree of saturation for lane group $j$ when adopting phase plan $k ; q_{j}$ - flow rate for lane group $j$ [veh/h]; $T$ - duration of analysis period [h]; $\kappa$ - incremental delay factor depending on controller settings; Iupstream filtering or metering adjustment factor.

By aggregating the average delays for all the lane groups, the average delay for the entire intersection (referred to as intersection delay) during the analysis period can be obtained in the following form:

$$
d_{k}=\frac{\sum_{j=1}^{m} T \cdot q_{j} \cdot d_{k j}}{\sum_{j=1}^{m} T \cdot q_{j}}, \forall \delta_{k}=1,
$$

where: $d_{k}$ - intersection delay when adopting phase plan $k$ [s/veh].

\subsection{Constraints}

To avoid lane overflow and blockage of lane entrance and make full use of the short left-turn lane, the effective green time for the lane group with a short left-turn lane should not be less than the full discharge time for the queue on the short left-turn lane, so we have:

$$
\begin{aligned}
& \left(\sum_{i=1}^{n_{k}} \phi_{k i j} \cdot g_{k i}\right) \geq g_{k j}^{c}, \\
& \forall \delta_{k}=1, S_{j}^{s}>0 .
\end{aligned}
$$

The effective green time for each lane group should not be less than a reasonable lower bound $g_{\min }$, that is:

$$
\left(\sum_{i=1}^{n_{k}} \phi_{k i j} \cdot g_{k i}\right) \geq g_{\min }, \forall \delta_{k}=1,
$$

where: $g_{\text {min }}-$ minimum effective green time for each lane group.

The sum of the effective green times for all phases plus the total lost time per cycle is equal to the cycle length which should be between the reasonable lower and upper bounds; thus:

$$
\begin{aligned}
& C_{\min } \leq \sum_{i=1}^{n_{k}} g_{k i}+L_{k} \leq C_{\max }, \\
& \forall \delta_{k}=1,
\end{aligned}
$$

where: $C_{\min }-$ minimum cycle length; $C_{\max }-$ maximum cycle length.

Another constraint is for available phase plans, i.e.:

$$
\sum_{k=1}^{n} \delta_{k}=1 \text {, }
$$

where: $n$ - number of signal phase plans. 
Finally, the effective green time per phase and the length of each short left-turn lane should be nonnegative, namely:

$$
g_{k i} \geq 0, D_{k j} \geq 0 .
$$

\subsection{Model Formulation and Solution Methods}

To find an optimal signal phase plan, green splits and required lane length, we may formulate the optimization models. In general, the transport management authorities wish to maximize the intersection capacity, whereas the road users aim at minimizing their travel delays. On the basis of our previous study (Yao, Zhang 2013), two optimization models are formulated as follows.

When minimizing the intersection delay under the aforementioned constraints, the optimization problem can be given by:

$$
\text { minimize } d=\sum_{k=1}^{n} \delta_{k} \cdot d_{k}=\sum_{k=1}^{n} \delta_{k} \cdot \frac{\sum_{j=1}^{m} T \cdot q_{j} \cdot d_{k j}}{\sum_{j=1}^{m} T \cdot q_{j}},
$$

constraints: Eqs (5)-(9).

When simultaneously maximizing the intersection capacity and minimizing the intersection delay under the same constraints, we can acquire a bi-objective optimization model, that is:

$$
\begin{aligned}
& \operatorname{maximize} Q=\sum_{k=1}^{n} \delta_{k} \cdot Q_{k}=\sum_{k=1}^{n} \delta_{k} \times \\
& \left(\sum_{j=1}^{m} \frac{1}{C_{k}} \cdot\left(S_{j}^{f} \cdot\left(\sum_{i=1}^{n_{k}} \phi_{k i j} \cdot g_{k i}\right)+S_{j}^{s} \cdot g_{k j}^{c}\right)\right) ; \\
& \operatorname{minimize} d=\sum_{k=1}^{n} \delta_{k} \cdot d_{k}=\sum_{k=1}^{n} \delta_{k} \cdot\left(\frac{\sum_{j=1}^{m} T \cdot q_{j} \cdot d_{k j}}{\sum_{j=1}^{m} T \cdot q_{j}}\right),
\end{aligned}
$$

constraints: Eqs (5)-(9).

Eq. (10) is a nonlinear single-objective optimization problem with linear and non-negativity constraints, which can be solved by the standard constrained nonlinear optimization methods such as the convex combination method. In this paper, they are solved using the fmincon function in MATLAB.

However, Eq. (11) is a bi-objective optimization problem, which can be indirectly solved using the fmincon function after being transformed into a single-objective optimization problem. According to Gan et al. (2005) and our previous studies (Yao 2013; Yao, Zhang 2013), the multiplication or division method is suitable for this conversion because the unit of capacity is different from that of delay. Therefore, Eq. (11) can be rewritten as:

$$
\operatorname{maximize} \frac{Q}{d}=\frac{\sum_{k=1}^{n} \delta_{k} \cdot Q_{k}}{\sum_{k=1}^{n} \delta_{k} \cdot d_{k}},
$$

constraints: Eqs (5)-(9).

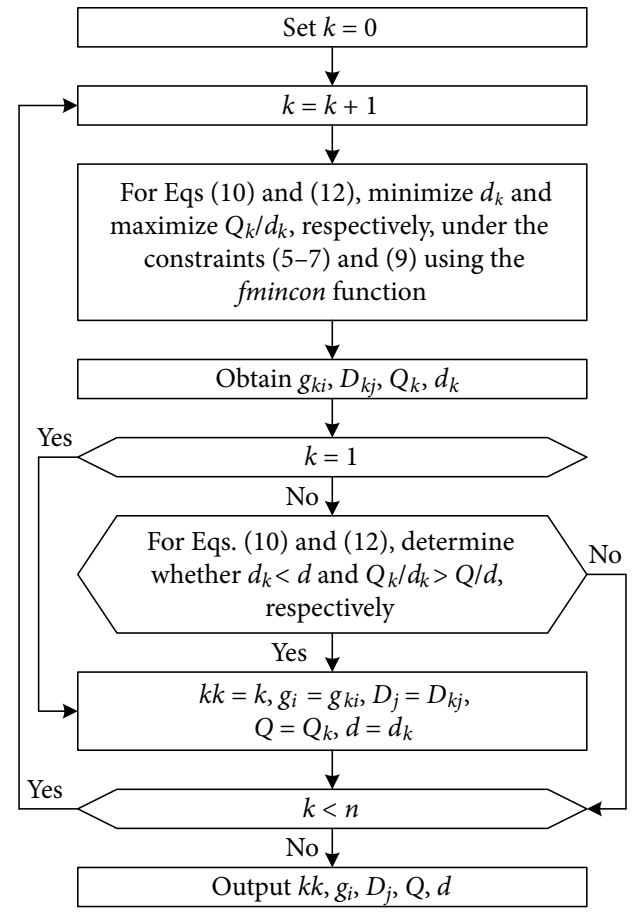

Fig. 5. Flowchart of solving the optimization models

As illustrated in Fig. 5, the flowchart is given to solve Eqs (10) and (12).

\subsection{Performance Measurement}

Generally speaking, traffic planners, designers or managers aim at maximizing the intersection capacity which is widely regarded as a performance index to evaluate traffic flow operations (Akçelik 1998; Highway Capacity Manual 2000). On the contrary, traffic users or travellers pursue minimizing their travel delay; thus, the intersection delay can also be regarded as another performance index to measure traffic flow operations (Webster, Cobbe 1966; Akçelik 1998; Highway Capacity Manual 2000).

To synthetically consider the above two aspects, we propose an integrative performance index to assess intersection operations. This integrative performance index is defined as the ratio of intersection capacity to intersection delay and named the capacity-to-delay ratio.

As stated before, the unit of intersection capacity is vehicles per hour, and that of intersection delay is seconds per vehicle. Therefore, the unit of capacity-to-delay ratio is square vehicles per hour per second.

\section{Numerical Examples}

\subsection{Consideration of Impact Factors}

The intersection under study is a four-leg intersection, as shown in Fig. 1, with the hourly traffic volume data for each movement on each approach presented in Table 1. Three cases are considered in terms of the intersection layout, i.e. only one full left-turn lane on each approach (denoted by FL), only one short left-turn lane on each approach (denoted by SL) and one full left-turn lane plus 
one short left-turn lane on each approach (denoted by Both).

Due to the fluctuation of traffic flow, peak 15-minute flow rates are used to obtain the optimal combination of the signal phase plan, green splits and required short-lane length, whereas the hourly volumes are used in evaluating the average operational performance of traffic flow. The peak 15-minute flow rate is equal to the ratio of the hourly volume to the peak-hour factor (denoted by PHF). Here we adopt the peak-hour factor to represent the demand distribution. Three levels of demand distributions are considered, i.e. $\mathrm{PHF}=0.85$, 0.90 , and 0.95 .

The initial values for the effective green time and short-lane length, which are denoted by $g_{0}$ and $D_{0}$ should be given beforehand. Because the initial effective green time and short-lane length all reflect the initial values of independent variables, we use a pair to describe them in order to analyse their impacts on the optimization results under the same parameter settings of the algorithm of solving the optimization models. Three sets of values are considered for them, i.e. $\left(g_{0}, D_{0}\right)=(5,18),(10,30)$ and $(15,42)$.

Any of the above factors may impact the results of the above-mentioned optimization models. Table 2 lists the selected levels and values of these factors. According to orthogonal experimental design (Wu 2012), Table 3 shows the orthogonal experimental scenarios, which consider all the combinations for these factors.

Table 1 . Hourly volumes for each approach

\begin{tabular}{|l|c|c|c|c|}
\hline \multirow{2}{*}{ Movement } & \multicolumn{4}{|c|}{ Hourly volume [veh/h] } \\
\cline { 2 - 5 } & $\begin{array}{c}\text { East- } \\
\text { bound } \\
\text { approach }\end{array}$ & $\begin{array}{c}\text { West- } \\
\text { bound } \\
\text { approach }\end{array}$ & $\begin{array}{c}\text { South- } \\
\text { bound } \\
\text { approach }\end{array}$ & $\begin{array}{c}\text { North- } \\
\text { bound } \\
\text { approach }\end{array}$ \\
\hline Left-turn & 400 & 500 & 300 & 300 \\
\hline Through & 700 & 540 & 730 & 600 \\
\hline Right-turn & 100 & 120 & 120 & 150 \\
\hline
\end{tabular}

Table 2. Levels and values of three impact factors

\begin{tabular}{|c|c|c|c|}
\hline Factors & $\begin{array}{c}\text { Initial values of } \\
\text { effective green time } \\
\text { and short-lane length } \\
\left(g_{0}, D_{0}\right)\end{array}$ & $\begin{array}{c}\text { Demand } \\
\text { distribution } \\
\text { (PHF) }\end{array}$ & $\begin{array}{c}\text { Intersection } \\
\text { layout } \\
\text { (Case) }\end{array}$ \\
\hline Level 1 & $g_{0} 1=5 \mathrm{~s}, D_{0} 1=18 \mathrm{~m}$ & PHF1 $=0.85$ & Case1 $=\mathrm{FL}$ \\
\hline Level 2 & $g_{0} 2=10 \mathrm{~s}, D_{0} 2=30 \mathrm{~m}$ & PHF2 $=0.90$ & Case2 $=\mathrm{SL}$ \\
\hline Level 3 & $g_{0} 3=15 \mathrm{~s}, D_{0} 3=42 \mathrm{~m}$ & PHF3 $=0.95$ & Case3 $=$ Both \\
\hline
\end{tabular}

\subsection{Model Parameters}

Based on Highway Capacity Manual (2000), we assume that traffic arrivals are random and there is no residual queue from the previous period at the start of the analysis period. The duration of the analysis period is chosen to be 1 hour. Thus, $P F, d_{3 k j}$ and $T$ are set to 1.0, 0 and 1.0, respectively. Because of pretimed signals and isolated intersections, $\kappa$ and $I$ are set to 0.5 and 1.0, respectively.
Table 3. Orthogonal experimental scenarios

\begin{tabular}{|c|c|c|c|}
\hline \multirow{2}{*}{$\begin{array}{l}\text { Test } \\
\text { num- } \\
\text { ber }\end{array}$} & \multicolumn{3}{|c|}{ Factors } \\
\hline & $g_{0}, D_{0}$ & PHF & Case \\
\hline No 1 & $g_{0} 1=5 \mathrm{~s}, D_{0} 1=18 \mathrm{~m}$ & PHF1 $=0.85$ & $=\mathrm{FL}$ \\
\hline No 2 & $g_{0} 1=5 \mathrm{~s}, D_{0} 1=18 \mathrm{~m}$ & PHF1 = 0.85 & Case $2=\mathrm{SL}$ \\
\hline No 3 & $g_{0} 1=5 \mathrm{~s}, D_{0} 1=18 \mathrm{~m}$ & PHF1 $=0.85$ & Case $3=$ Both \\
\hline No 4 & $g_{0} 1=5 \mathrm{~s}, D_{0} 1=18 \mathrm{~m}$ & PHF2 $=0.90$ & Case $1=$ FL \\
\hline No 5 & $g_{0} 1=5 \mathrm{~s}, D_{0} 1=18 \mathrm{~m}$ & PHF2 $=0.90$ & Case $2=\mathrm{SL}$ \\
\hline No 6 & $g_{0} 1=5 \mathrm{~s}, D_{0} 1=18 \mathrm{~m}$ & PHF2 $=0.90$ & Case $3=$ Both \\
\hline No 7 & $g_{0} 1=5 \mathrm{~s}, D_{0} 1=18 \mathrm{~m}$ & PHF3 $=0.95$ & Case $1=\mathrm{FL}$ \\
\hline No 8 & $g_{0} 1=5 \mathrm{~s}, D_{0} 1=18 \mathrm{~m}$ & PHF3 $=0.95$ & Case $2=\mathrm{SL}$ \\
\hline No 9 & $g_{0} 1=5 \mathrm{~s}, D_{0} 1=18 \mathrm{~m}$ & PHF3 $=0.95$ & Case $3=$ Both \\
\hline No 10 & $2=10 \mathrm{~s}, D_{0} 2=30 \mathrm{~m}$ & PHF1 $=0.85$ & $=\mathrm{FL}$ \\
\hline No 11 & $2=10 \mathrm{~s}, D_{0} 2=30 \mathrm{~m}$ & PHF1 $=0.85$ & Case $2=\mathrm{SL}$ \\
\hline No 12 & $2=10 \mathrm{~s}, D_{0} 2=30 \mathrm{~m}$ & PHF1 = & $3=$ Both \\
\hline No 13 & $2=10 \mathrm{~s}, D_{0} 2=30 \mathrm{~m}$ & PHF2 $=0.90$ & Case 1 = FL \\
\hline No 14 & $0^{2}=10 \mathrm{~s}, D_{0} 2=30 \mathrm{~m}$ & PHF2 = & $=\mathrm{SL}$ \\
\hline No 15 & $0^{2}=10 \mathrm{~s}, D_{0} 2=30 \mathrm{~m}$ & PHF2 $=0.90$ & Case $3=$ Both \\
\hline No 16 & $g_{0} 2=10 \mathrm{~s}, D_{0} 2=30 \mathrm{~m}$ & PHF3 $=0.95$ & Case $1=\mathrm{FL}$ \\
\hline No 17 & $g_{0} 2=10 \mathrm{~s}, D_{0} 2=30 \mathrm{~m}$ & PHF3 $=0.95$ & Case2 $=\mathrm{SL}$ \\
\hline No 18 & $g_{0} 2=10 \mathrm{~s}, D_{0} 2=30 \mathrm{~m}$ & PHF3 $=0.95$ & Case $3=$ Both \\
\hline No 19 & $g_{0} 3=15 \mathrm{~s}, D_{0} 3=42 \mathrm{~m}$ & PHF1 $=0.85$ & Case $1=$ FL \\
\hline No 20 & $g_{0} 3=15 \mathrm{~s}, D_{0} 3=42 \mathrm{~m}$ & PHF1 $=0.85$ & Case2 $=\mathrm{SL}$ \\
\hline No 21 & $g_{0} 3=15 \mathrm{~s}, D_{0} 3=42 \mathrm{~m}$ & PHF1 $=0.85$ & Case $3=$ Both \\
\hline No 22 & $g_{0} 3=15 \mathrm{~s}, D_{0} 3=42 \mathrm{~m}$ & PHF2 $=0.90$ & Case $1=\mathrm{FL}$ \\
\hline No 23 & $g_{0} 3=15 \mathrm{~s}, D_{0} 3=42 \mathrm{~m}$ & PHF2 $=0.90$ & Case2 $=\mathrm{SL}$ \\
\hline No 24 & $g_{0} 3=15 \mathrm{~s}, D_{0} 3=42 \mathrm{~m}$ & PHF2 $=0.90$ & Case $3=$ Both \\
\hline No 25 & $g_{0} 3=15 \mathrm{~s}, D_{0} 3=42 \mathrm{~m}$ & PHF3 $=0.95$ & Case $1=\mathrm{FL}$ \\
\hline No 26 & $g_{0} 3=15 \mathrm{~s}, D_{0} 3=42 \mathrm{~m}$ & PHF3 $=0.95$ & Case $2=$ SL \\
\hline No 27 & $g_{0} 3=15 \mathrm{~s}, D_{0} 3=42 \mathrm{~m}$ & PHF3 $=0.95$ & Case $3=$ Both \\
\hline
\end{tabular}

For a signal phase plan, the total lost time per cycle is the product of the number of discrete phases and the average lost time per phase. The number of discrete phases can be determined by using the ring diagram (Roess et al. 2010). According to our previous studies (Yao 2013; Yao, Zhang 2013), the average lost time per phase is set to $3.5 \mathrm{~s}$, the average saturation headway between consecutive vehicles is $2 \mathrm{~s}$ and the average queue spacing between consecutive vehicles is $6 \mathrm{~m}$. In addition, the minimum effective green time for each movement is assumed to be $10 \mathrm{~s}$ (RTRA 2003), the amber and all-red times are respectively set to 3 and $2 \mathrm{~s}$ and the minimum and maximum cycle lengths are set to 60 and $150 \mathrm{~s}$, respectively (Highway Capacity Manual 2000).

\subsection{Orthogonal Experiments}

Table 4 lists the optimization results of the orthogonal experiments when minimizing the intersection delay and maximizing the capacity-to-delay ratio under different conditions. These results provide the signal phase 
plan, required short-lane length and cycle length as well as the intersection capacity and delay, the degree of saturation, and the capacity-to-delay ratio. The former three values are obtained by solving the optimization models and using the peak 15-minute flow rates, whereas the latter four values are recalculated using the hourly volumes after the independent variables in the optimization models are ascertained.

Based on the data in Table 4, we can make the following points:

- the optimal signal phase plan under case FL may be different from that under case SL while the cycle length, the degree of saturation, the intersection capacity and delay under case FL are the same as or very close to those under case SL when the other conditions are identical;

- the optimal signal phase plan under case Both is different from that under the other two cases, the short-lane length, cycle length, intersection delay and degree of saturation under case Both are all less than those under the other two cases, whereas the intersection capacity and capacityto-delay ratio under case Both are all larger than those under the other two cases when the other conditions are identical, which indicates that installing both a full left-turn lane and a short leftturn lane for an approach is obviously better than installing a full or short left-turn lane only;

- the optimization results obtained by minimizing the intersection delay is slightly better than those by maximizing the capacity-to-delay ratio in view of the capacity-to-delay ratio for the entire intersection.

The range analysis of the orthogonal experimental results is given in Table 5. It can be seen that the range of the capacity-to-delay ratio obtained by 'Case' is maximal, that obtained by 'PHF' is medium and that obtained by ' $g_{0}, D_{0}$ ' is minimal. Based on orthogonal experimental design ( $\mathrm{Wu}$ 2012), the more the range of a performance index obtained by a factor is, the more important this factor is for the impact on the performance index. Therefore, the primary factor, which has an effect on the optimization models is whether a short left-turn lane is added on an approach, the secondary factor is the demand distribution, and the least factor is the initial values of the effective green time and short-lane length.

Table 4. Optimization results of orthogonal experiments

\begin{tabular}{|c|c|c|c|c|c|c|c|c|c|c|c|}
\hline \multirow{2}{*}{$\begin{array}{l}\text { Objective } \\
\text { function }\end{array}$} & \multirow{2}{*}{$\begin{array}{c}\text { Test } \\
\text { number }\end{array}$} & \multicolumn{10}{|c|}{ Optimization values of independent variables and performance indices } \\
\hline & & OPP & $D_{1}[\mathrm{~m}]$ & $D_{3}[\mathrm{~m}]$ & $D_{5}[\mathrm{~m}]$ & $D_{7}[\mathrm{~m}]$ & $C[\mathrm{~s}]$ & $Q[\mathrm{veh} / \mathrm{h}]$ & $d[\mathrm{~s} / \mathrm{veh}]$ & $X$ & $\mathrm{Q} / d\left[\mathrm{veh}^{2} / \mathrm{h} / \mathrm{s}\right]$ \\
\hline \multirow{27}{*}{ minimize $d$} & No 1 & SPP6 & - & - & - & - & 150.0000 & 5090.0328 & 104.4452 & 0.9063 & 48.7340 \\
\hline & No 2 & SPP6 & 75.8086 & 112.3122 & 75.8086 & 112.3122 & 150.0000 & 5090.0291 & 104.4444 & 0.9063 & 48.7344 \\
\hline & No 3 & SPP5 & 30.5874 & 48.7762 & 33.8864 & 49.3358 & 93.7932 & 6204.2708 & 39.8345 & 0.7401 & 155.7513 \\
\hline & No 4 & SPP7 & - & - & - & - & 150.0000 & 5060.0422 & 101.3122 & 0.9094 & 49.9450 \\
\hline & No 5 & SPP5 & 72.7528 & 114.2918 & 82.1999 & 114.2918 & 150.0000 & 5060.0394 & 101.3119 & 0.9094 & 49.9452 \\
\hline & No 6 & SPP6 & 30.0000 & 43.6851 & 30.0000 & 44.3096 & 86.1557 & 6107.6220 & 38.0195 & 0.7522 & 160.6444 \\
\hline & No 7 & SPP7 & - & - & - & - & 150.0000 & 5018.1291 & 96.2169 & 0.9152 & 52.1543 \\
\hline & No 8 & SPP7 & 74.2281 & 118.7002 & 82.1046 & 118.7002 & 150.0000 & 5018.1196 & 96.2165 & 0.9152 & 52.1545 \\
\hline & No 9 & SPP5 & 30.0000 & 39.9522 & 30.0000 & 40.6131 & 80.8129 & 6028.6943 & 37.0853 & 0.7636 & 162.5628 \\
\hline & No 10 & SPP6 & - & - & - & - & 150.0000 & 5090.0286 & 104.4445 & 0.9063 & 48.7343 \\
\hline & No 11 & SPP6 & 75.8089 & 112.3120 & 75.8089 & 112.3120 & 150.0000 & 5090.0279 & 104.4443 & 0.9063 & 48.7344 \\
\hline & No 12 & SPP9 & 30.5877 & 48.7761 & 33.8886 & 49.3387 & 93.7958 & 6204.3006 & 39.8351 & 0.7401 & 155.7494 \\
\hline & No 13 & SPP7 & - & - & - & - & 150.0000 & 5060.0405 & 101.3120 & 0.9094 & 49.9451 \\
\hline & No 14 & SPP7 & 72.7529 & 114.2924 & 82.2001 & 114.2924 & 150.0000 & 5060.0335 & 101.3111 & 0.9094 & 49.9455 \\
\hline & No 15 & SPP6 & 30.0000 & 43.6862 & 30.0000 & 44.3088 & 86.1550 & 6107.6124 & 38.0194 & 0.7522 & 160.6447 \\
\hline & No 16 & SPP5 & - & - & - & - & 150.0000 & 5018.1287 & 96.2170 & 0.9152 & 52.1543 \\
\hline & No 17 & SPP5 & 74.2276 & 118.6986 & 82.1042 & 118.6986 & 150.0000 & 5018.1366 & 96.2177 & 0.9152 & 52.1540 \\
\hline & No 18 & SPP11 & 30.0000 & 39.9483 & 30.0000 & 40.6139 & 80.8129 & 6028.6947 & 37.0853 & 0.7636 & 162.5629 \\
\hline & No 19 & SPP6 & - & - & - & - & 150.0000 & 5090.0287 & 104.4443 & 0.9063 & 48.7344 \\
\hline & No 20 & SPP6 & 75.8084 & 112.3124 & 75.8084 & 112.3124 & 150.0000 & 5090.0291 & 104.4443 & 0.9063 & 48.7344 \\
\hline & No 21 & SPP5 & 30.5894 & 48.7807 & 33.8889 & 49.3386 & 93.7978 & 6204.3238 & 39.8356 & 0.7401 & 155.7481 \\
\hline & No 22 & SPP7 & - & - & - & - & 150.0000 & 5060.0384 & 101.3118 & 0.9094 & 49.9452 \\
\hline & No 23 & SPP7 & 72.7540 & 114.2913 & 82.1999 & 114.2913 & 150.0000 & 5060.0383 & 101.3116 & 0.9094 & 49.9453 \\
\hline & No 24 & SPP6 & 30.0000 & 43.6865 & 30.0000 & 44.3085 & 86.1545 & 6107.6057 & 38.0193 & 0.7522 & 160.6450 \\
\hline & No 25 & SPP7 & - & - & - & - & 150.0000 & 5018.1311 & 96.2167 & 0.9152 & 52.1545 \\
\hline & No 26 & SPP7 & 74.2274 & 118.7008 & 82.1029 & 118.7008 & 150.0000 & 5018.1240 & 96.2164 & 0.9152 & 52.1546 \\
\hline & No 27 & SPP11 & 30.0000 & 39.9555 & 30.0000 & 40.6143 & 80.8145 & 6028.7192 & 37.0855 & 0.7636 & 162.5626 \\
\hline
\end{tabular}


End of Table 4

\begin{tabular}{|c|c|c|c|c|c|c|c|c|c|c|c|}
\hline \multirow{2}{*}{$\begin{array}{l}\text { Objective } \\
\text { function }\end{array}$} & \multirow{2}{*}{$\begin{array}{c}\text { Test } \\
\text { number }\end{array}$} & \multicolumn{10}{|c|}{ Optimization values of independent variables and performance indices } \\
\hline & & OPP & $D_{1}[\mathrm{~m}]$ & $D_{3}[\mathrm{~m}]$ & $D_{5}[\mathrm{~m}]$ & $D_{7}[\mathrm{~m}]$ & $C[\mathrm{~s}]$ & $Q[\mathrm{veh} / \mathrm{h}]$ & $d$ [s/veh] & $X$ & $\mathrm{Q} / d\left[\mathrm{veh}^{2} / \mathrm{h} / \mathrm{s}\right]$ \\
\hline \multirow{27}{*}{$\begin{array}{l}\operatorname{maximize} \\
Q / d\end{array}$} & No 1 & SPP6 & - & - & - & - & 150.0000 & 5113.3087 & 108.2468 & 0.9040 & 47.2375 \\
\hline & No 2 & SPP6 & 74.4951 & 110.7973 & 74.4951 & 110.7973 & 150.0000 & 5113.2848 & 108.2428 & 0.9040 & 47.2390 \\
\hline & No 3 & SPP5 & 33.0339 & 52.2786 & 36.4763 & 53.1192 & 99.8818 & 6270.6387 & 41.3961 & 0.7322 & 151.4791 \\
\hline & No 4 & SPP7 & - & - & - & - & 150.0000 & 5071.4655 & 102.8559 & 0.9081 & 49.3065 \\
\hline & No 5 & SPP5 & 72.2635 & 113.4359 & 81.6271 & 113.4359 & 150.0000 & 5071.4438 & 102.8507 & 0.9081 & 49.3088 \\
\hline & No 6 & SPP10 & 30.0000 & 44.9838 & 30.0000 & 45.7870 & 88.1947 & 6135.2313 & 38.4877 & 0.7485 & 159.4078 \\
\hline & No 7 & SPP5 & - & - & - & - & 150.0000 & 5033.8523 & 96.8595 & 0.9132 & 51.9707 \\
\hline & No 8 & SPP13 & 73.9480 & 116.3793 & 81.5045 & 118.0618 & 150.0000 & 5033.9040 & 96.8598 & 0.9132 & 51.9710 \\
\hline & No 9 & SPP10 & 30.0000 & 41.8355 & 30.0000 & 42.7357 & 83.7591 & 6073.4769 & 37.5410 & 0.7569 & 161.7823 \\
\hline & No 10 & SPP6 & - & - & - & - & 150.0000 & 5113.2902 & 108.2432 & 0.9040 & 47.2389 \\
\hline & No 11 & SPP6 & 74.4918 & 110.8005 & 74.4918 & 110.8005 & 150.0000 & 5113.2854 & 108.2421 & 0.9040 & 47.2393 \\
\hline & No 12 & SPP11 & 33.0331 & 52.2761 & 36.4770 & 53.1202 & 99.8812 & 6270.6330 & 41.3959 & 0.7322 & 151.4794 \\
\hline & No 13 & SPP5 & - & - & - & - & 150.0000 & 5071.4538 & 102.8525 & 0.9081 & 49.3080 \\
\hline & No 14 & SPP5 & 72.1898 & 113.4059 & 81.6506 & 113.4059 & 150.0000 & 5071.8964 & 102.9540 & 0.9080 & 49.2637 \\
\hline & No 15 & SPP10 & 30.0000 & 44.9845 & 30.0000 & 45.7862 & 88.1938 & 6135.2196 & 38.4875 & 0.7485 & 159.4083 \\
\hline & No 16 & SPP5 & - & - & - & - & 150.0000 & 5033.9108 & 96.8600 & 0.9132 & 51.9710 \\
\hline & No 17 & SPP5 & 73.9486 & 116.3698 & 81.5049 & 118.0597 & 150.0000 & 5033.9474 & 96.8615 & 0.9132 & 51.9706 \\
\hline & No 18 & SPP10 & 30.0000 & 41.8327 & 30.0000 & 42.7354 & 83.7587 & 6073.4720 & 37.5410 & 0.7569 & 161.7825 \\
\hline & No 19 & SPP6 & - & - & - & - & 150.0000 & 5113.2661 & 108.2393 & 0.9040 & 47.2404 \\
\hline & No 20 & SPP6 & 74.4935 & 110.7958 & 74.4935 & 110.7958 & 150.0000 & 5113.3101 & 108.2473 & 0.9040 & 47.2373 \\
\hline & No 21 & SPP5 & 33.0334 & 52.2779 & 36.4761 & 53.1193 & 99.8812 & 6270.6328 & 41.3959 & 0.7322 & 151.4794 \\
\hline & No 22 & SPP5 & - & - & - & - & 150.0000 & 5071.4507 & 102.8515 & 0.9081 & 49.3085 \\
\hline & No 23 & SPP5 & 72.2634 & 113.4349 & 81.6275 & 113.4349 & 150.0000 & 5071.4508 & 102.8521 & 0.9081 & 49.3082 \\
\hline & No 24 & SPP6 & 30.0000 & 44.9857 & 30.0000 & 45.7871 & 88.1947 & 6135.2311 & 38.4877 & 0.7485 & 159.4077 \\
\hline & No 25 & SPP7 & - & - & - & - & 150.0000 & 5033.8901 & 96.8600 & 0.9132 & 51.9708 \\
\hline & No 26 & SPP5 & 73.9459 & 116.3792 & 81.5025 & 118.0630 & 150.0000 & 5033.9161 & 96.8601 & 0.9132 & 51.9710 \\
\hline & No 27 & SPP10 & 30.0000 & 41.8351 & 30.0000 & 42.7356 & 83.7589 & 6073.4743 & 37.5410 & 0.7569 & 161.7824 \\
\hline
\end{tabular}

Note: OPP - the optimal signal phase plan; $D_{1}, D_{3}, D_{5}$ and $D_{7}$ - the lengths of the short left-turn lanes in lane groups $1,3,5$ and 7, respectively; $C$ - cycle length; $Q$ - intersection capacity; $d$ - intersection delay; $X$ - intersection degree of saturation; $Q / d$ capacity-to-delay ratio.

Table 5. Range analysis of orthogonal experimental results

\begin{tabular}{|c|c|c|c|c|}
\hline \multirow{2}{*}{ Objective function } & \multicolumn{4}{|c|}{$\mathrm{Q} / d\left[\mathrm{veh}^{2} / \mathrm{h} / \mathrm{s}\right]$} \\
\hline & Factors & $\left(g_{0}, D_{0}\right)$ & PHF & Case \\
\hline \multirow{5}{*}{ minimize $d$} & Average for level 1 & 86.7362 & 84.4061 & 50.2779 \\
\hline & Average for level 2 & 86.7361 & 86.8450 & 50.2780 \\
\hline & Average for level 3 & 86.7360 & 88.9572 & 159.6523 \\
\hline & Range & 0.0002 & 4.5511 & 109.3744 \\
\hline & Primary and secondary factors & \multicolumn{3}{|c|}{ Case $\rightarrow$ PHF $\rightarrow\left(g_{0}, D_{0}\right)$} \\
\hline \multirow{5}{*}{$\operatorname{maximize} Q / d$} & Average for level 1 & 85.5225 & 81.9856 & 49.5058 \\
\hline & Average for level 2 & 85.5180 & 86.0031 & 49.5010 \\
\hline & Average for level 3 & 85.5229 & 88.5747 & 157.5565 \\
\hline & Range & 0.0049 & 6.5891 & 108.0555 \\
\hline & Primary and secondary factors & \multicolumn{3}{|c|}{ Case $\rightarrow$ PHF $\rightarrow\left(g_{0}, D_{0}\right)$} \\
\hline
\end{tabular}


Based on the aforementioned analysis, when leftturn traffic is relatively heavy, it is suggested that a short left-turn lane adjacent to a full left-turn lane should be added so long as road space is allowable.

Table 6 lists the design values of the cycle length, actual green time and short-lane length, which obtained from each experimental scenario. It can be seen that the objective function, demand distribution and intersection layout all have their impacts on the optimal signal phase plan, cycle length, green splits, and required short-lane length; the cycle length, the actual green time for each movement and the design length of each short-lane mainly depend on the number of left-turn lanes and the demand distribution.

\subsection{Simulation Tests}

As stated before, the formulated models can optimize the signal phase plan. However, they could not optimize the signal phase sequence. According to the Guidelines for Traffic Signals (RiLSA) (RTRA 2003), the signal phase sequence has an important effect on traffic flow opera- tions. Based on Tables 4 and 6, the short-lane lengths on the eastbound, westbound, southbound and northbound approaches are respectively set to $42,42,36$ and $30 \mathrm{~m}$ and the corresponding signal phase plan is SPP5 in Fig. 3. To investigate the impacts of signal phase sequences on traffic flow operations, we rearrange the phase sequence of the components in SPP5. Therefore, four feasible signal timing plans which are denoted by STP1, STP2, STP3 and STP4 can be obtained, as shown in Fig. 6.

The microscopic traffic simulation software VISSIM is used to simulate traffic flow operations under different signal phase sequences. The hourly traffic volumes in Table 1 are used as the inputs and the simulation length is set to $3600 \mathrm{~s}$. In addition, the multi-run mode is adopted and the number of runs is set to 10 .

To evaluate traffic flow operations, the travel time sections, queue counters and nodes are created, as illustrated in Fig. 7. The length between the start and destination sections is $120 \mathrm{~m}$ for each movement, each queue counter locates at the corresponding stopline and the node refers to the intersection under investigation.

Table 6. Design values of cycle length, actual green time and short-lane length

\begin{tabular}{|c|c|c|c|c|c|c|c|c|c|c|c|c|c|c|c|}
\hline \multirow{2}{*}{$\begin{array}{l}\text { Objective } \\
\text { function }\end{array}$} & \multirow{2}{*}{$\begin{array}{c}\text { Test } \\
\text { number }\end{array}$} & \multirow{2}{*}{ OPP } & \multirow{2}{*}{$C[\mathrm{~s}]$} & \multicolumn{8}{|c|}{ Actual green time $[\mathrm{s}]$} & \multicolumn{4}{|c|}{ Short-lane length [m] } \\
\hline & & & & $G_{1}$ & $G_{2}$ & $G_{3}$ & $G_{4}$ & $G_{5}$ & $G_{6}$ & $G_{7}$ & $G_{8}$ & $D_{1}$ & $D_{3}$ & $D_{5}$ & $D_{7}$ \\
\hline \multirow{27}{*}{ minimize $d$} & No 1 & SPP6 & 150 & 24 & 37 & 36 & 34 & 24 & 37 & 36 & 34 & - & - & - & - \\
\hline & No 2 & SPP6 & 150 & 24 & 37 & 36 & 34 & 24 & 37 & 36 & 34 & 78 & 114 & 78 & 114 \\
\hline & No 3 & SPP5 & 94 & 9 & 26 & 15 & 24 & 10 & 25 & 15 & 24 & 36 & 54 & 36 & 54 \\
\hline & No 4 & SPP7 & 150 & 23 & 37 & 37 & 34 & 26 & 34 & 37 & 34 & - & - & - & - \\
\hline & No 5 & SPP5 & 150 & 23 & 37 & 37 & 34 & 26 & 34 & 37 & 34 & 78 & 120 & 84 & 120 \\
\hline & No 6 & SPP6 & 86 & 9 & 23 & 13 & 22 & 9 & 23 & 13 & 21 & 30 & 48 & 30 & 48 \\
\hline & No 7 & SPP7 & 150 & 23 & 36 & 38 & 33 & 26 & 33 & 38 & 33 & - & - & - & - \\
\hline & No 8 & SPP7 & 150 & 23 & 36 & 38 & 33 & 26 & 33 & 38 & 33 & 78 & 120 & 84 & 120 \\
\hline & No 9 & SPP5 & 81 & 9 & 21 & 12 & 20 & 9 & 21 & 12 & 19 & 30 & 42 & 36 & 42 \\
\hline & No 10 & SPP6 & 150 & 24 & 37 & 36 & 34 & 24 & 37 & 36 & 34 & - & - & - & - \\
\hline & No 11 & SPP6 & 150 & 24 & 37 & 36 & 34 & 24 & 37 & 36 & 34 & 78 & 114 & 78 & 114 \\
\hline & No 12 & SPP9 & 94 & 9 & 26 & 15 & 24 & 10 & 25 & 15 & 24 & 36 & 54 & 36 & 54 \\
\hline & No 13 & SPP7 & 150 & 23 & 37 & 37 & 34 & 26 & 34 & 37 & 34 & - & - & - & - \\
\hline & No 14 & SPP7 & 150 & 23 & 37 & 37 & 34 & 26 & 34 & 37 & 34 & 78 & 120 & 84 & 120 \\
\hline & No 15 & SPP6 & 86 & 9 & 23 & 13 & 22 & 9 & 23 & 13 & 21 & 30 & 48 & 30 & 48 \\
\hline & No 16 & SPP5 & 150 & 23 & 36 & 38 & 33 & 26 & 33 & 38 & 33 & - & - & - & - \\
\hline & No 17 & SPP5 & 150 & 23 & 36 & 38 & 33 & 26 & 33 & 38 & 33 & 78 & 120 & 84 & 120 \\
\hline & No 18 & SPP11 & 81 & 9 & 21 & 12 & 20 & 9 & 21 & 12 & 19 & 30 & 42 & 30 & 42 \\
\hline & No 19 & SPP6 & 150 & 24 & 37 & 36 & 34 & 24 & 37 & 36 & 34 & - & - & - & - \\
\hline & No 20 & SPP6 & 150 & 24 & 37 & 36 & 34 & 24 & 37 & 36 & 34 & 78 & 114 & 78 & 114 \\
\hline & No 21 & SPP5 & 94 & 9 & 26 & 15 & 24 & 10 & 25 & 15 & 24 & 36 & 54 & 36 & 54 \\
\hline & No 22 & SPP7 & 150 & 23 & 37 & 37 & 34 & 26 & 34 & 37 & 34 & - & - & - & - \\
\hline & No 23 & SPP7 & 150 & 23 & 37 & 37 & 34 & 26 & 34 & 37 & 34 & 78 & 120 & 84 & 120 \\
\hline & No 24 & SPP6 & 86 & 9 & 23 & 13 & 22 & 9 & 23 & 13 & 21 & 30 & 48 & 30 & 48 \\
\hline & No 25 & SPP7 & 150 & 23 & 36 & 38 & 33 & 26 & 33 & 38 & 33 & - & - & - & - \\
\hline & No 26 & SPP7 & 150 & 23 & 36 & 38 & 33 & 26 & 33 & 38 & 33 & 78 & 120 & 84 & 120 \\
\hline & No 27 & SPP11 & 81 & 9 & 21 & 12 & 20 & 9 & 21 & 12 & 19 & 30 & 42 & 30 & 42 \\
\hline
\end{tabular}


End of Table 6

\begin{tabular}{|c|c|c|c|c|c|c|c|c|c|c|c|c|c|c|c|}
\hline \multirow{2}{*}{$\begin{array}{l}\text { Objective } \\
\text { function }\end{array}$} & \multirow{2}{*}{$\begin{array}{c}\text { Test } \\
\text { number }\end{array}$} & \multirow{2}{*}{ OPP } & \multirow{2}{*}{$C[\mathrm{~s}]$} & \multicolumn{8}{|c|}{ Actual green time $[\mathrm{s}]$} & \multicolumn{4}{|c|}{ Short-lane length [m] } \\
\hline & & & & $G_{1}$ & $G_{2}$ & $G_{3}$ & $G_{4}$ & $G_{5}$ & $G_{6}$ & $G_{7}$ & $G_{8}$ & $D_{1}$ & $D_{3}$ & $D_{5}$ & $D_{7}$ \\
\hline \multirow{27}{*}{$\begin{array}{l}\operatorname{maximize} \\
Q / d\end{array}$} & No 1 & SPP6 & 150 & 23 & 37 & 35 & 34 & 23 & 37 & 35 & 34 & - & - & - & - \\
\hline & No 2 & SPP6 & 150 & 23 & 37 & 35 & 34 & 23 & 37 & 35 & 34 & 78 & 114 & 78 & 114 \\
\hline & No 3 & SPP5 & 100 & 10 & 28 & 16 & 26 & 11 & 27 & 16 & 26 & 36 & 54 & 42 & 54 \\
\hline & No 4 & SPP7 & 150 & 23 & 37 & 36 & 34 & 26 & 34 & 36 & 34 & - & - & - & - \\
\hline & No 5 & SPP5 & 150 & 23 & 37 & 36 & 34 & 26 & 34 & 36 & 34 & 78 & 114 & 84 & 114 \\
\hline & No 6 & SPP10 & 88 & 9 & 24 & 13 & 22 & 9 & 24 & 14 & 22 & 30 & 48 & 30 & 48 \\
\hline & No 7 & SPP5 & 150 & 23 & 36 & 37 & 34 & 26 & 33 & 38 & 33 & - & - & - & - \\
\hline & No 8 & SPP13 & 150 & 23 & 36 & 37 & 34 & 26 & 33 & 38 & 33 & 78 & 120 & 84 & 120 \\
\hline & No 9 & SPP10 & 84 & 9 & 22 & 12 & 21 & 9 & 22 & 13 & 20 & 30 & 42 & 30 & 48 \\
\hline & No 10 & SPP6 & 150 & 23 & 37 & 35 & 34 & 23 & 37 & 35 & 34 & - & - & - & - \\
\hline & No 11 & SPP6 & 150 & 23 & 37 & 35 & 34 & 23 & 37 & 35 & 34 & 78 & 114 & 78 & 114 \\
\hline & No 12 & SPP11 & 100 & 10 & 28 & 16 & 26 & 11 & 27 & 16 & 26 & 36 & 54 & 42 & 54 \\
\hline & No 13 & SPP5 & 150 & 23 & 37 & 36 & 34 & 26 & 34 & 36 & 34 & - & - & - & - \\
\hline & No 14 & SPP5 & 150 & 23 & 37 & 36 & 34 & 26 & 34 & 36 & 34 & 78 & 114 & 84 & 114 \\
\hline & No 15 & SPP10 & 88 & 9 & 24 & 13 & 22 & 9 & 24 & 14 & 22 & 30 & 48 & 30 & 48 \\
\hline & No 16 & SPP5 & 150 & 23 & 36 & 37 & 34 & 26 & 33 & 38 & 33 & - & - & - & - \\
\hline & No 17 & SPP5 & 150 & 23 & 36 & 37 & 34 & 26 & 33 & 38 & 33 & 78 & 120 & 84 & 120 \\
\hline & No 18 & SPP10 & 84 & 9 & 22 & 12 & 21 & 9 & 22 & 13 & 20 & 30 & 42 & 30 & 48 \\
\hline & No 19 & SPP6 & 150 & 23 & 37 & 35 & 34 & 23 & 37 & 35 & 34 & - & - & - & - \\
\hline & No 20 & SPP6 & 150 & 23 & 37 & 35 & 34 & 23 & 37 & 35 & 34 & 78 & 114 & 78 & 114 \\
\hline & No 21 & SPP5 & 100 & 10 & 28 & 16 & 26 & 11 & 27 & 16 & 26 & 36 & 54 & 42 & 54 \\
\hline & No 22 & SPP5 & 150 & 23 & 37 & 36 & 34 & 26 & 34 & 36 & 34 & - & - & - & - \\
\hline & No 23 & SPP5 & 150 & 23 & 37 & 36 & 34 & 26 & 34 & 36 & 34 & 78 & 114 & 84 & 114 \\
\hline & No 24 & SPP6 & 88 & 9 & 24 & 13 & 22 & 9 & 24 & 14 & 22 & 30 & 48 & 30 & 48 \\
\hline & No 25 & SPP7 & 150 & 23 & 36 & 37 & 34 & 26 & 33 & 38 & 33 & - & - & - & - \\
\hline & No 26 & SPP5 & 150 & 23 & 36 & 37 & 34 & 26 & 33 & 38 & 33 & 78 & 120 & 84 & 120 \\
\hline & No 27 & SPP10 & 84 & 9 & 22 & 12 & 21 & 9 & 22 & 13 & 20 & 30 & 42 & 30 & 48 \\
\hline
\end{tabular}

Note: $G_{1} \sim G_{8}$ - actual green times for lane groups $1 \sim 8$, respectively; the meaning of the other symbols is the same as shown in Table 4. The actual green time means the duration of the green indication for a lane group or movement, and is equal to the effective green time plus the start-up lost time and then minus the amber time for the lane group. The calculated values of the cycle length and actual green time are converted into the design values by omitting decimal fractions smaller than 0.5 and counting all others, including 0.5 , as 1 . The design value of short-lane length rounds its calculated value to the nearest integer towards infinity that is the multiple of the average queue spacing between consecutive vehicles (assuming $6 \mathrm{~m}$ in this paper).

Four performance indices are selected: vehicle throughput, average delay, average queue length and average number of stops.

Fig. 8 illustrates the impacts of different signal phase sequences on the intersection performance. It can be seen that:

- the variation in the average delay, queue length and number of stops under each signal phase sequence is consistent whereas the variation in the vehicle throughput varies a lot;

- the operations of the eastbound and westbound movements are rarely affected by the signal phase sequence in either direction whereas the operations of the southbound and northbound movements are affected by the signal phase sequence in the south-north direction and not affected by that in the east-west direction.
The results reveal that the priority of the through and left-turn movements on an approach may be very significant for traffic flow operations, especially in the presence of short left-turn lanes.

Table 7 lists the results of the node evaluation for the entire intersection, which indicates that the signal phase sequence greatly affects intersection operations. By comparing Fig. 8 and Table 7, it can be seen that the signal phase sequence is a key factor for the southnorth direction where the length of the left-turn bay is relatively short. This observation shows that, when the length of the left-turn bay is relatively short on a specified approach, the leading green phasing is superior to the lagging green phasing for the corresponding movements; otherwise, there is no obvious difference between the leading green phasing and the lagging green phasing. 

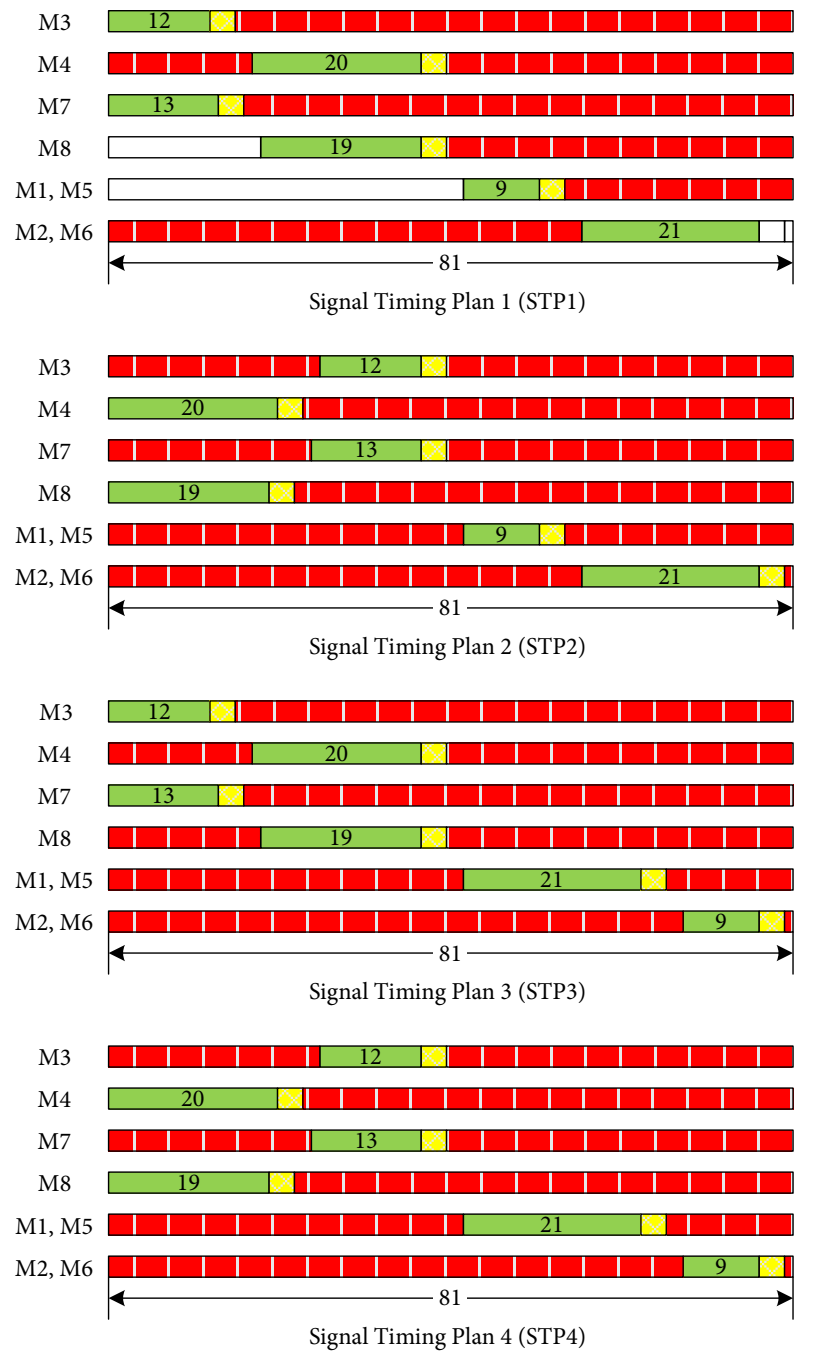

$\square$ Green $\square$ Amber $\square \square$ Red

Fig. 6. All feasible signal timing plans

Table 7. Results of node evaluation for the entire intersection

\begin{tabular}{|c|c|c|c|c|}
\hline Scenario & $\begin{array}{c}\text { Vehicle } \\
\text { throughput } \\
\text { [veh/h] }\end{array}$ & $\begin{array}{c}\text { Average } \\
\text { delay } \\
\text { [s/veh] }\end{array}$ & $\begin{array}{c}\text { Average } \\
\text { queue } \\
\text { length [m] }\end{array}$ & $\begin{array}{c}\text { Average } \\
\text { number } \\
\text { of stops }\end{array}$ \\
\hline STP1 & 4477.70 & 33.07 & 27.38 & 0.872 \\
\hline STP2 & 4476.60 & 32.90 & 27.60 & 0.861 \\
\hline STP3 & 3613.60 & 99.94 & 151.40 & 2.172 \\
\hline STP4 & 3588.70 & 100.30 & 151.74 & 2.174 \\
\hline
\end{tabular}

\section{Discussions and Suggestions}

The formulated optimization models in this paper can obtain the optimal combination of signal phase plan, green splits and required short-lane length to maximize intersection capacity and minimize intersection delay. When the actual short-lane length is greater than the required value for any lane group, the intersection capacity will not continue to increase and the intersection delay will not continue to decrease, as listed in Table 4. On the contrary, the maximal intersection capacity and the minimal intersection delay could not be attained. a)

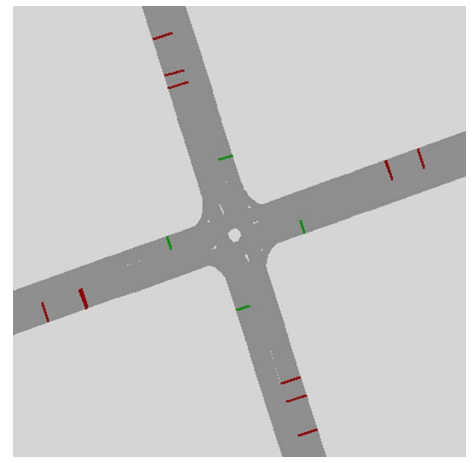

b)

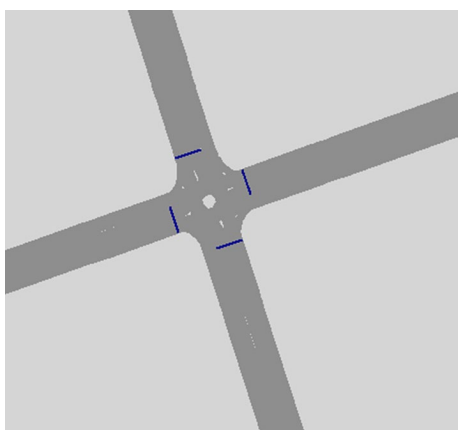

c)

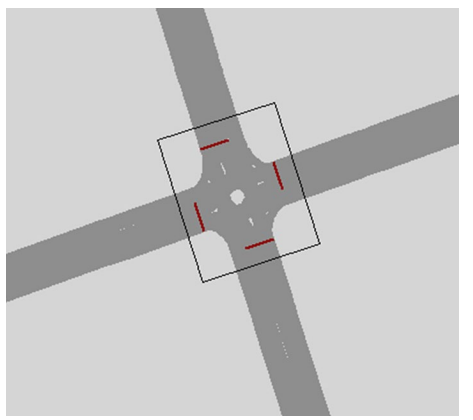

Fig. 7. Settings of the selected performance evaluations in VISSIM: $\mathrm{a}$ - travel time sections; $\mathrm{b}$ - queue counters; $\mathrm{c}$ - stoplines and nodes

The above-mentioned results are based on a 1-hour analysis period. However, traffic flow always fluctuates during a day. Thus, multiple analysis periods are usually created for which different signal phase plans and signal timings are adopted. However, the intersection layout including the short-lane length remains unchanged for a long period. Therefore, a five-stage procedure in Fig. 9 is proposed to apply the recommended models in practice. Here is a description of the function for each stage:

- in Stage 1, the basic intersection layout and all typical signal phase plans are determined on the basis of the variation in traffic flow.

- in Stage 2, the optimal signal phase plan, cycle length, green splits and required short-lane length are obtained for each analysis period using the recommended models.

- in Stage 3, the suitable length of each short leftturn lane need be determined during a long period. If there is no short left-turn lane at an intersection, this stage can be skipped.

- in Stage 4, given the length of each short left-turn lane, the optimal signal phase plan, cycle length 


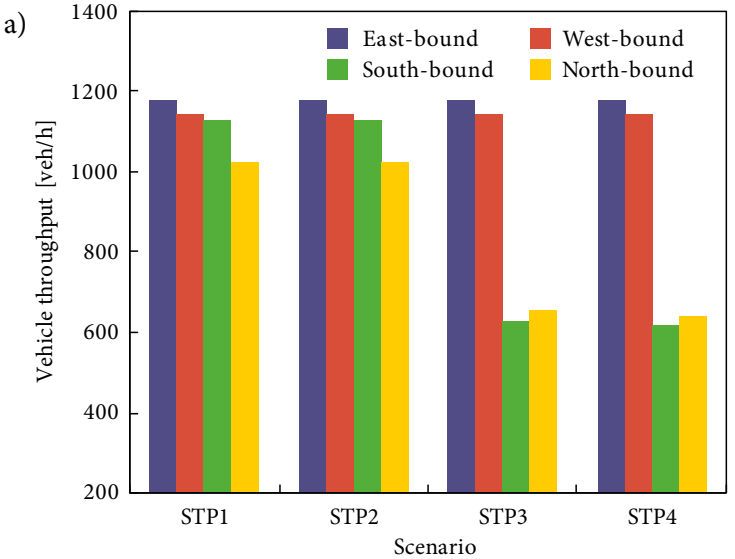

b)

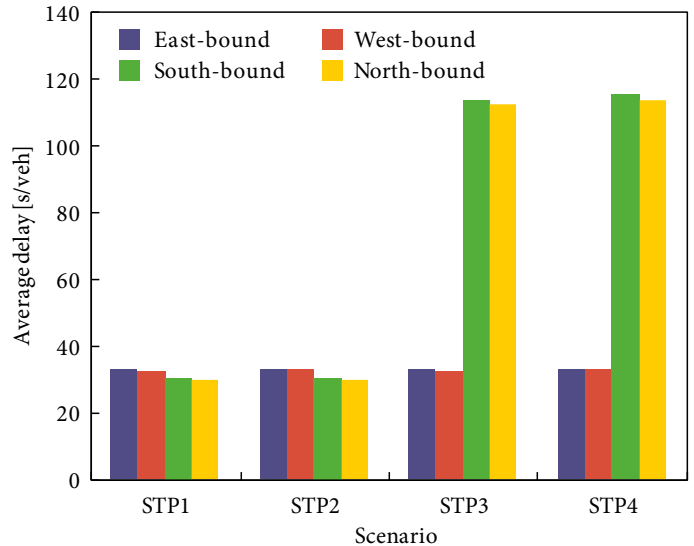

c)

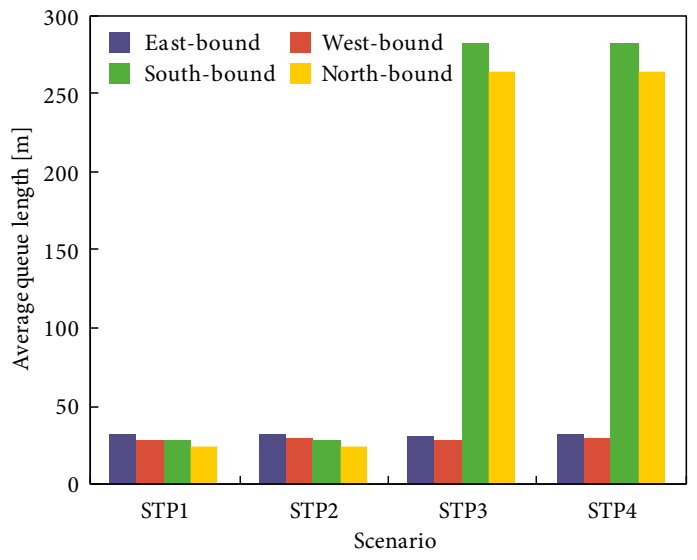

d)

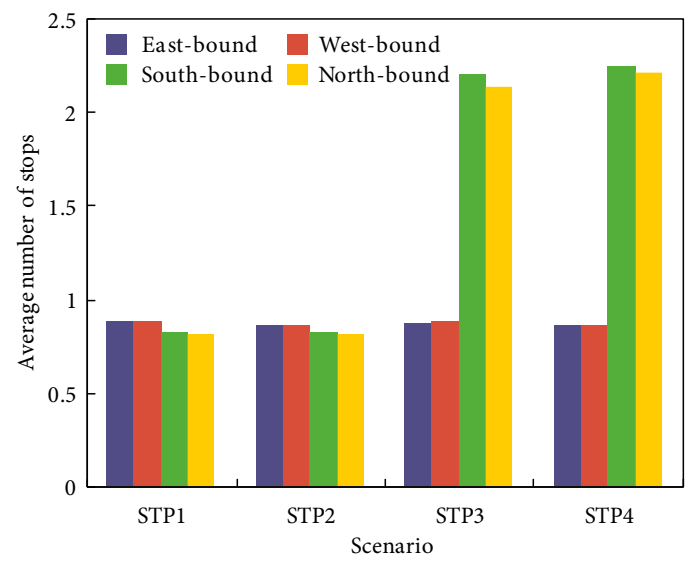

Fig. 8. Impacts of different signal phase sequences on traffic flow operations: $\mathrm{a}$ - vehicle throughput; $\mathrm{b}$ - average delay; $c$ - average queue length; $d$ - average number of stops and green splits can be selected for each analysis period; then, the cycle length and the green time per phase can be determined for practical applications.

- in Stage 5, the intersection performances under different signal phase sequences are compared via simulation test or field measurement, and the optimal signal phase sequence and signal timing plan can be determined for each analysis period.

In this paper, the short-lane length is regarded as an independent variable. According to the relevant literature (Roess et al. 2010), an intersection can be regarded as an isolated intersection when the distance between adjacent intersections is longer than one mile. Based on this, an upper limit is not set for the short-lane length because an isolated intersection is studied in the paper. If the optimized short-lane length is relatively long, the length of the common section between adjacent intersections should be adopted. For this case, the short leftturn lane would be a full left-turn lane. If two adjacent intersections are relatively close, they could not be regarded as isolated intersections. This case will go beyond the research range of this paper.

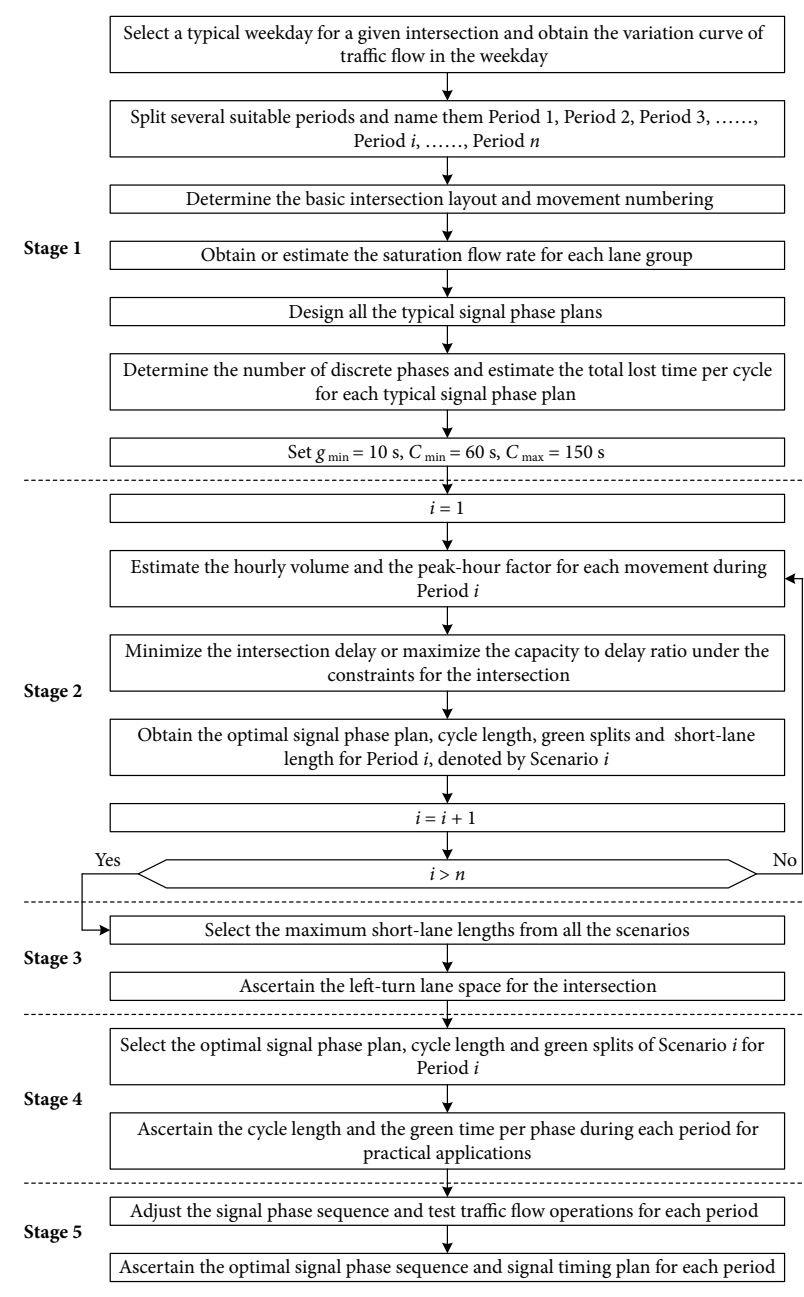

Fig. 9. Flowchart of using the recommended models in practice 


\section{Conclusions}

To enhance the capacity and level of service of signalized intersections, one or more short left-turn lanes are often added. The capacity of an intersection depends not only on the length of each short left-turn lane and the effective green time per phase but also on the signal phase plan. Thus, all typical signal phase plans for a four-leg intersection with protected left-turn phases are first proposed by using the dual-ring design. Based on our previous studies, the efforts have been made in this paper to improve the calculation of the capacity of a lane group, which makes the resulting models suitable for the lane group with or without a short left-turn lane.

To determine an optimal allocation of the timespace resources of an isolated signalized intersection, two optimization models are formulated to seek for minimum intersection delay and simultaneous optimization of intersection capacity and delay, respectively. To illustrate the effectiveness of these models, numerical examples are designed. The orthogonal experimental outcomes show that the optimized results and resulting intersection performance depend on both intersection layout and demand distribution, whereas they have nothing to do with the initial values of effective green times and short-lane lengths. It is found that the number of left-turn lanes plays a most influential role while the demand distribution takes the second position. In addition, the optimal signal phase plan may vary under different conditions. The impacts of signal phase sequences on intersection operations are investigated under the assumption that the components of each signal phase plan and green splits are the same. The simulated results show that the signal phase sequence can be an important impact factor for intersection operations and the leading green phasing is better than the lagging green phasing when the left-turn bay length is relatively short for a given approach. Finally, two variations of the proposed models are recommended for application in practice and the flowchart of using each of these models in practice has been presented in this paper.

The contribution of this paper is fourfold. First, the formulation of the lane group capacity at an intersection is improved so that it is applicable to signalized intersections with or without short left-turn lanes. Second, two optimization models are formulated to obtain the optimal combination of signal phase plan, green splits and required short-lane length for isolated signalized intersections under two different objectives, i.e. minimum intersection delay and simultaneous optimization of intersection capacity and delay, respectively. Third, based on the range analysis of the orthogonal experiments, the primary factor, which affects the optimal solutions of the optimization models is whether a short left-turn lane is added on an approach; according to the simulation analysis, the signal phase sequence may have an important effect on intersection operations. Last, but not least, the use of the recommended models in practice has been discussed in detail.

\section{Acknowledgements}

This research was partly supported by the National Natural Science Foundation of China (Grant No 51578111, 51308092 and 71171026) and the Doctoral Fund of Ministry of Education of China (Grant No 20110041120009).

The support of these agencies or organizations is gratefully acknowledged.

Any opinions, findings, and conclusions or recommendations expressed in this paper are those of the authors and do not necessarily reflect the views of these funding bodies.

\section{References}

Akçelik, R. 1998. Traffic Signals: Capacity and Timing Analysis. Research Report ARR 123. 108 p. Available from Internet: http://www.arrb.com.au/admin/file/content13/c6/ARR\%20 123.pdf

Highway Capacity Manual. 2000. Transportation Research Board. $1134 \mathrm{p}$.

Gan, Y. A. 2005. Operations Research. Tsinghua University Press, Beijing, China. (in Chinese).

Kikuchi, S.; Kii, M.; Chakroborty, P. 2004. Lengths of double or dual left-turn lanes, Transportation Research Record: Journal of the Transportation Research Board 1881: 72-78. https://doi.org/10.3141/1881-09

Kikuchi, S.; Kronprasert, N.; Kii, M. 2007. Lengths of turn lanes on intersection approaches: three-branch fork lanes: left-turn, through, and right-turn lanes, Transportation Research Record: Journal of the Transportation Research Board 2023: 92-101. https://doi.org/10.3141/2023-10

Koonce, P.; Rodegerdts, L.; Lee, K.; Quayle, S.; Beaird, S.; Braud, C.; Bonneson, J.; Tarnoff, P.; Urbanik, T. 2008. Traffic Signal Timing Manual. Publication No FHWAHOP-08-024. US Department of Transportation, Federal Highway Administration, Washington, DC, US. 274 p. Available from Internet: https://ops.fhwa.dot.gov/publications/fhwahop08024/fhwa_hop_08_024.pdf

Lam, W. H. K.; Poon, A. C. K.; Mung, G. K. S. 1997. Integrated model for lane-use and signal-phase designs, Journal of Transportation Engineering 123(2): 114-122.

https://doi.org/10.1061/(ASCE)0733-947X(1997)123:2(114)

Qi, Y.; Yu, L.; Azimi, M.; Guo, L. 2007. Determination of storage lengths of left-turn lanes at signalized intersections, Transportation Research Record: Journal of the Transportation Research Board 2023: 102-111. https://doi.org/10.3141/2023-11

Qi, Y. G.; Guo, L.; Yu, L.; Teng, H. 2012. Estimation of design lengths of left-turn lanes, Journal of Transportation Engineering 138(3): 274-283. https://doi.org/10.1061/(ASCE)TE.1943-5436.0000299

RTRA. 2003. Guidelines for Traffic Signals (RiLSA). Road and Transportation Research Association (RTRA). 182 p.

Roess, R. P.; Prassas, E. S.; McShane, W. R. 2010. Traffic Engineering. 4th edition. Pearson. $744 \mathrm{p}$.

Tian, Z. Z.; Wu, N. 2006. Probabilistic model for signalized intersection capacity with a short right-turn lane, Journal of Transportation Engineering 132(3): 205-212. https://doi.org/10.1061/(ASCE)0733-947X(2006)132:3(205)

Webster, F. V. 1958. Traffic Signal Settings. Road Research Technical Paper No 39. Road Research Laboratory. Her Majesty's Stationery Office, England. 44 p. 
Webster, F. V.; Cobbe, B. M. 1966. Traffic Signals. Road Research Technical Paper No 56. Road Research Laboratory. Her Majesty's Stationery Office, England. 111 p.

Wong, C. K.; Heydecker, B. G. 2011. Optimal allocation of turns to lanes at an isolated signal-controlled junction, Transportation Research Part B: Methodological 45(4): 667-681. https://doi.org/10.1016/j.trb.2010.12.001

Wong, C. K.; Wong, S. C. 2003. Lane-based optimization of signal timings for isolated junctions, Transportation Research Part B: Methodological 37(1): 63-84. https://org/10.1016/S0191-2615(01)00045-5

Wu, G. C. 2012. Probability Theory and Mathematical Statistics. Beijing, China: China Renmin University Press (in Chinese).

$\mathrm{Wu}$, N. 2011. Modelling blockage probability and capacity of shared lanes at signalized intersections, Procedia - Social and Behavioral Sciences 16: 481-491. https://doi.org/10.1016/j.sbspro.2011.04.469

$\mathrm{Wu}, \mathrm{N}$. 2007. Total approach capacity at signalized intersections with shared and short lanes: generalized model based on a simulation study, Transportation Research Record: Journal of the Transportation Research Board 2027: 19-26. https://doi.org/10.3141/2027-03

Yang, J.; Zhou, H. 2011. Integrating left-turn lane geometric design with signal timing, Journal of Transportation Engineering 137(11): 767-774.

https://doi.org/10.1061/(ASCE)TE.1943-5436.0000282

Yao, R. 2013. Sensitivity analysis of optimization models for isolated intersections with short left-turn lanes on approaches, Journal of Advanced Transportation 47(1): 28-42. https://doi.org/10.1002/atr.1185

Yao, R.; Zhang, H. M. 2013. Optimal allocation of lane space and green splits of isolated signalized intersections with short left-turn lanes, Journal of Transportation Engineering 139(7): 667-677.

https://doi.org/10.1061/(ASCE)TE.1943-5436.0000551

Yin, K.; Zhang, Y.; Wang, B. 2011. Modeling delay during heavy traffic for signalized intersections with short leftturn bays, Transportation Research Record: Journal of the Transportation Research Board 2257: 103-110. https://doi.org/10.3141/2257-12

Yin, K.; Zhang, Y.; Wang, B. 2010. Analytical models for protected plus permitted left-turn capacity at signalized intersection with heavy traffic, Transportation Research Record: Journal of the Transportation Research Board 2192: 177184. https://doi.org/10.3141/2192-17

Zhang, Y.; Tong, J. 2008. Modeling left-turn blockage and capacity at signalized intersection with short left-turn bay, Transportation Research Record: Journal of the Transportation Research Board 2071: 71-76.

https://doi.org/10.3141/2071-09 